Article

\title{
Formula Development of Red Palm (Elaeis guineensis) Fruit Extract Loaded with Solid Lipid Nanoparticles Containing Creams and Its Anti-Aging Efficacy in Healthy Volunteers
}

\author{
Thipapun Plyduang ${ }^{1,2}$, Apichart Atipairin ${ }^{1,2}$, Attawadee Sae Yoon ${ }^{1,2}$, Namfa Sermkaew ${ }^{1,2}$, Pajaree Sakdiset ${ }^{1,2}$ \\ and Somchai Sawatdee $1,2, *$ (D) \\ 1 Drug and Cosmetics Excellence Center, Walailak University, Thasala, Nakhon Si Thammarat 80161, Thailand; \\ thipapun.pl@wu.ac.th (T.P.); apichart.at@wu.ac.th (A.A.); attawadee.sa@wu.ac.th (A.S.Y.); \\ namfa.se@wu.ac.th (N.S.); pajaree.sa@wu.ac.th (P.S.) \\ 2 School of Pharmacy, Walailak University, Thasala, Nakhon Si Thammarat 80161, Thailand \\ * Correspondence: somchai086@hotmail.com or somchai.sa@wu.ac.th
}

\section{check for}

updates

Citation: Plyduang, T.; Atipairin, A.; Sae Yoon, A.; Sermkaew, N.;

Sakdiset, P.; Sawatdee, S. Formula Development of Red Palm (Elaeis guineensis) Fruit Extract Loaded with Solid Lipid Nanoparticles Containing Creams and Its Anti-Aging Efficacy in Healthy Volunteers. Cosmetics 2022, 9,3. https://doi.org/10.3390/ cosmetics 9010003

Academic Editor: Piera Di Martino

Received: 15 November 2021

Accepted: 22 December 2021

Published: 24 December 2021

Publisher's Note: MDPI stays neutral with regard to jurisdictional claims in published maps and institutional affiliations.

Copyright: (C) 2021 by the authors. Licensee MDPI, Basel, Switzerland. This article is an open access article distributed under the terms and conditions of the Creative Commons Attribution (CC BY) license (https:// creativecommons.org/licenses/by/ $4.0 /)$.

\begin{abstract}
Palm fruits (Elaeis guineensis) comprise antioxidants that can be used as skin care agents. This study developed a cosmeceutical cream containing E. guineensis extract, loaded with solid lipid nanoparticles (SLNs), and assessed its efficacy on female volunteers. The E. guineensis extract exhibited a good antioxidant activity with high levels of vitamin E, $\beta$-carotene, and palmitic acid. Day and night creams containing E. guineensis fruit extract, loaded with SLNs, were formulated and exhibited acceptable physical characteristics and good stability. Subsequently, their clinical efficacy and safety were evaluated on female volunteers. Both creams were non-irritating and had good cutaneous compatibility. Skin hydration, transepidermal water loss (TEWL), skin elasticity, melanin index, and skin texture were measured before and $30 \mathrm{~min}$ after the first application, as well as after 7 , 14 , and 30 days of daily application. A satisfactory survey was implemented using a questionnaire, and volunteer satisfaction scores were high for the product's performance. Overall, the results showed that skin hydration, TEWL, cutaneous elasticity, and melanin index were improved, compared to the baseline data, after 30 days. Thus, the formulated facial day and night creams made the skin moist, reduced wrinkles, increased elasticity, and cleared the skin to the consumers' satisfaction.
\end{abstract}

Keywords: Elaeis guineensis extract; antioxidant activity; stability; skin hydration; skin elasticity; satisfactory survey; irritation

\section{Introduction}

Genetics, age, and UV exposure play a role in deteriorating skin, which is a serious concern for women. Reduced epidermal and dermal thickness, as well as decreased water content in the stratum corneum, cause the skin to appear "dry." The ability of dermal fibroblasts to produce collagen fibers becomes impaired, resulting in lower collagen content and denatured intradermal elastic fibers that lose elasticity. Year after year, the components of the extracellular matrix of the dermis, such as hyaluronic acid, decrease. Wrinkles, loosening, and drooping are all caused by these factors [1,2].

The palm fruit (Elaeis guineensis) is a tropical tree crop grown in Africa, Asia, and along tropical belts in Latin America. It is the source of palm oil, an internationally traded edible oil that is an essential source of nourishment. As phytonutrients may be extracted from palm fruit oil, they offer many potential health benefits. Palm oil is commonly used in dermatology for skin care, treatment of several dermatological disorders, and oil massage [3]. Palm oil contains a high concentration of antioxidative phytonutrients, accounting for $1 \%$ of its crude weight. Vitamin E (tocopherols and tocotrienols), carotenoids, phytosterols, squalene, phospholipids, coenzyme Q10, and phenolics are the most common compounds found 
in palm oil. Anti-cancer, cardio-protection, anti-angiogenesis, cholesterol-inhibition, neuroprotection, pro-vitamin A, and anti-diabetic activities are among the key health benefits offered by palm oil. Red palm oil also includes highly accessible $\alpha$ - and $\beta$-carotenes, both of which have pro-vitamin A properties. Combating vitamin A deficiency in infants and pregnant women, decreasing ocular problems, enhancing management of hypobaric situations, and protection against infection are only a few health benefits linked to vitamin A [4]. Carotenoids have a significant potential role as biological antioxidants, protecting cells, tissues, and subsequently, human epidermis, from free radical damage [5]. Vitamin E from palm oil is widely known as the major chain breaking antioxidant and the first line of defense in protecting lipid membranes from peroxidation [6]. Tocopherols and tocotrienols are powerful antioxidants that have a variety of health benefits, including reducing skin aging and fat oxidation [5]. The fatty acid composition of palm oil has a higher proportion of palmitic acid than any other fatty acid [7,8]. Furthermore, the E. guineensis extracts exhibited wound-healing capabilities [6,9]. Thus, E. guineensis is enriched with active compounds suitable for the development of cosmeceutical anti-aging products. E. guineensis oil and its derivatives have been prepared as delivery systems to deliver drug or active compounds, such as nanoemulsion-based [10,11], emulgel-based [12], nanostructured lipid carriers [13], and ester-based nano-cream [14]. However, there is a lack of report on using E. guineensis extract as antioxidant ingredients in cosmeceutical products.

Solid lipid nanoparticles (SLNs) are a new category of nanoparticulate active substance vehicles gaining traction as topical medication carriers. SLNs are submicron-sized (50-1000 nm) lipid components $[15,16]$ that remain solid at room temperature and comprise physiologically tolerable lipid components. To overcome the limitations of SLNs alone, SLNs may be combined with polymeric nanoparticles, fat emulsions, and liposomes [17]. SLNs have been employed to regulate medication delivery and for selective targeting because they are biocompatible and biodegradable [16]. They have the potential for simple and large-scale production with low toxicity [15]. SLNs offer advantages over other carriers, such as creams, tinctures, and emulsions because of their controlled release, minimal skin irritation, and active component protection. SLN can aid medication penetration into the skin, maintain prolonged release to minimize systemic absorption, and reduce skin irritation by acting as an ultraviolet (UV) sunscreen system. Skin targeting was also discovered to be a property of SLNs. Some studies have reported the preparation of SLN, encapsulated with plant extracts or using palm oil in the systems, showed loading efficacy and stability of all SLN delivery systems were excellent [18-22]. As the red palm oil is heat stable, creating no mutagens when heated [23], the method of preparation of SLN, using high temperature, may not affect the quality of the palm oil or extract. The creation of $E$. guineensis fruit extract, encapsulated in SLN, is intriguing because it protects an unstable component, improves skin transport, and increases topical product performance [17].

The purpose of this study was to develop cosmeceutical day and night creams containing E. guineensis extract encapsulated in SLN technology. Then, to assess the efficacy and safety of these products on the aging skin of women, 25-50 years of age. The entire experiment is illustrated in Figure 1. 

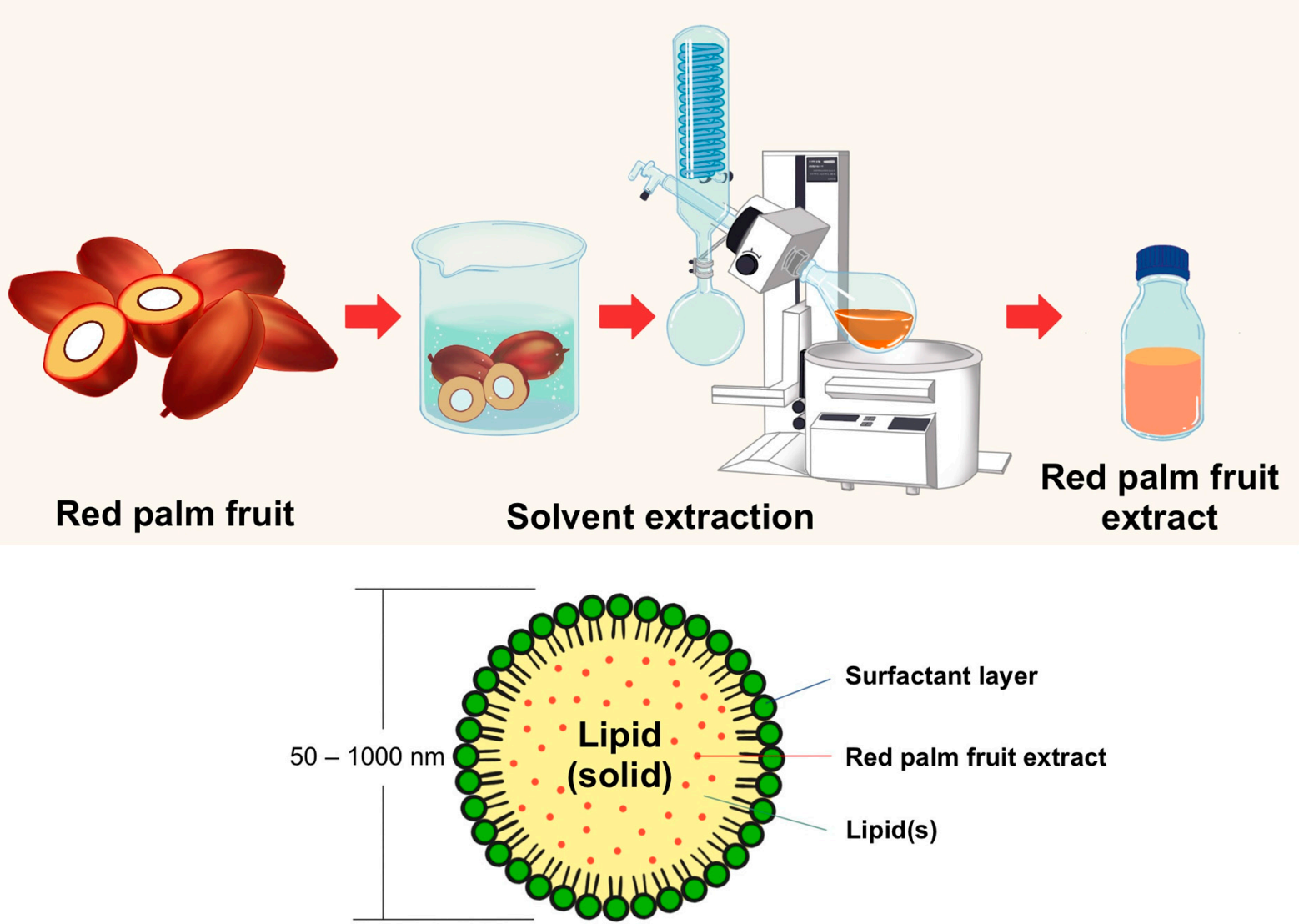

\section{Red palm fruit extract loaded solid lipid nanoparticles}

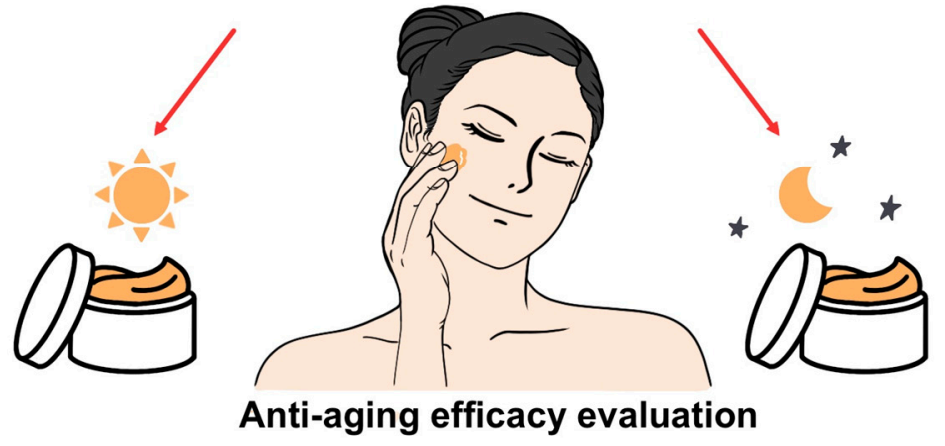

Figure 1. Overview of the experimental design. Schematic of the extraction of red palm fruits (Elaeis guineensis) by maceration with rotary evaporation, encapsulation in solid lipid nanoparticles (SLNs), preparation of day and night creams, and evaluation of their skin efficacy in human volunteers.

\section{Materials and Methods}

\subsection{Materials}

Purchased from Sigma-Aldrich ${ }^{\circledR}$ (Darmstadt, Germany) were 2,2-Diphenyl-2 picrylhydrazyl, ascorbic acid, glyceryl monostearate-SE, and Triton X-100. Cyclomethicone/ cyclopentasiloxane and titanium dioxide (15 nm particle size liquid) were obtained from MySkinRecipes ${ }^{\circledR}$ (Bangkok, Thailand). Caffeine, carbopol 940, cetyl alcohol, coconut oil, dimethicone, disodium ethylene diamine tetra-acetic acid (EDTA), glycerin, isopropyl myristate, liquid paraffin, menthol, octyl dimethyl cinnamate, phenoxyethanol, polyethylene glycol 400, potassium hydroxide, propylene glycol, silicone oil, sodium hydroxide, Span ${ }^{\circledR} 60$, Span ${ }^{\circledR} 80$, Tween ${ }^{\circledR} 60$, Tween ${ }^{\circledR} 80$, stearic acid, tocopherol acetate, triethanolamine, white soft paraffin, and peppermint oil were purchased from P. C. Drug 
Center Co. Ltd. (Bangkok, Thailand). Methanol, ethanol, denatured ethanol, hexane, and diethyl ether were procured from RCI Labscan (Bangkok, Thailand).

\subsection{Preparation of E. guineensis Fruit Extract}

\subsubsection{Plant Collection}

Palm fruits (E. guineensis) were collected from a local farm in Surat Thani Province, Thailand and used as the sample for extraction within 1 week. Palm fruits were washed and rinsed with purified water to remove dust and contaminants, and then, air-dried at room temperature before further experiments.

\subsubsection{Extraction of E. guineensis}

The cleaned red palm fruits were cut into small pieces, and the palm seeds were removed before pulverization. The cleaned pulverized palm fruits were kept in a refrigerator $\left(2-8{ }^{\circ} \mathrm{C}\right)$ within 3 days before the extraction. Finely crushed palm fruit $(100 \mathrm{~g})$ from the pulverization process was soaked in $1 \mathrm{~L}$ of $95 \%$ ethanol for $24 \mathrm{~h}$, and then filtered twice with filter cloth and filter paper to remove fiber from the solution. The solution (top layer) and fat (bottom layer) were separated using a separatory funnel. Subsequently, fat was extracted twice with $1 \mathrm{~L}$ of $95 \%$ ethanol. The whole solution was combined, and the solvent was removed using a rotary evaporator (Rotavapor ${ }^{\circledR}$ R210, Büchi, Essen, Germany) [24]. The obtained compound was used to prepare SLNs within three days after the extraction was completed.

\subsection{Evaluation of E. guineensis Fruit Extract}

\subsubsection{Physical Properties}

The appearance of the E. guineensis fruit extract was recorded for organoleptic characteristics (color, smell, and product clarity). The $\mathrm{pH}$ value was measured using a digital calibrated $\mathrm{pH}$ meter (SevenEasy ${ }^{\mathrm{TM}} \mathrm{pH}$, Mettler Toledo, Greifensee, Switzerland). The $\mathrm{pH}$ values were determined three times and reported as the mean \pm standard deviation.

\subsubsection{Determination of Total Vitamin E Content}

Determination of tocopherol and tocotrienol in the palm extract was conducted with a minor adaptation, according to a previous study [25]. An HPLC (Ultimate 3000, Thermo Scientific, Karlsruhe, Germany), coupled with a photodiode array detector, was used for the analyses of palm tocols. The column used was silica $4.6 \mathrm{~mm}$ i.d. $\times 250 \mathrm{~mm}$ length (ProteCol ${ }^{\mathrm{TM}}$, SGE Analytical Science Pty., Ltd., Tokyo, Japan). Chromatography was performed using heptane and ethyl acetate $(95: 5 v / v)$ as the mobile phase. The flow rate was $1 \mathrm{~mL} / \mathrm{min}$. The E. guineensis fruit extract was dissolved in heptane until a clear solution was obtained and used for sample preparation. Different concentrations of standard tocopherol and tocotrienol $(4-12 \mu \mathrm{g} / \mathrm{mL})$ were injected under the same conditions.

\subsubsection{Determination of $\beta$-Carotene Content}

Chromatographic separations were performed on an Ultimate 3000 HPLC system (Thermo Scientific, Germany) equipped with a UV detector and Chromelon software to analyze the chromatogram. A reversed-phase column (C18, ProteCol ${ }^{\mathrm{TM}}$ SGE Analytical Science Pty., Ltd., Japan; $5 \mu \mathrm{m}, 250 \mathrm{~mm} \times 4.6 \mathrm{~mm}$ I.D.) was used at an ambient temperature and protected with a precolumn (ProteCol ${ }^{\mathrm{TM}}$ SGE Analytical Science Pty., Ltd., Japan). Chromatograms were monitored at $450 \mathrm{~nm}$. The mobile phase was acetonitrile:2propanol:ethyl acetate $(40: 40: 20, v / v / v)$; the flow rate was $0.8 \mathrm{~mL} / \mathrm{min}$ [26]. The E. guineensis fruit extracts, obtained as described above, were dissolved in the mobile phase $(1 \mathrm{~mL})$, filtered through a $0.45-\mu \mathrm{m}$ membrane disc (Schleicher and Schtill, Dassel, Germany), and injected into the chromatograph (injection volume, $10 \mu \mathrm{L}$ ). Stock solutions of standard $\beta$-carotene $(0.25 \mathrm{mg} / \mathrm{mL})$ were prepared in petroleum ether (boiling point, $\left.40-60{ }^{\circ} \mathrm{C}\right)$. The concentrations of the standard solutions were determined spectrophotometrically using the corresponding reported extinction coefficient values. Aliquots $(10-200 \mu \mathrm{L})$ were evaporated 
to dryness in a nitrogen stream, and the residues were dissolved in the mobile phase $(1 \mathrm{~mL})$ and subjected to HPLC, as described above.

\subsubsection{Determination of Fatty Acid Content}

The fatty acid composition of the E. guineensis fruit extract was determined by gas chromatography, according to a literature report [27]. Approximately $100 \mathrm{mg}$ of E. guineensis fruit extract was placed in a screw-cap glass tube. Margaric acid solution $(0.1 \mathrm{~mL}$, $10 \mathrm{mg} / \mathrm{mL})$, used as the internal standard, and $1.5 \mathrm{~mL}$ of $\mathrm{NaOH}$ in methanol $(0.5 \mathrm{~N})$ were added to the tube, and nitrogen was blown into the tube for $15 \mathrm{~s}$. The tube was tightly covered and vortexed using a vortex (model G560E, Scientific Industries Inc., Bohemia, NY, USA), heated in a water bath (model WPE45, Memmert, Schwabach, Germany) for $5 \mathrm{~min}$ at $87^{\circ} \mathrm{C}$, and then cooled. Furthermore, $2 \mathrm{~mL}$ of boron trifluoride $\left(\mathrm{BF}_{3}\right)$ in methanol $(14 \% \mathrm{w} / \mathrm{v})$ was added to the tube, vortexed, and then nitrogen was blown into the tube. The tube was covered tightly, heated for $30 \mathrm{~min}$ at $87^{\circ} \mathrm{C}$, and then cooled. In this stage, fatty acids are converted to fatty acid methyl esters (FAMEs). The extracting solvent, $1 \mathrm{~mL}$ of hexane, was added, and the mixture was vortexed. Furthermore, $3 \mathrm{~mL}$ of saturated $\mathrm{NaCl}$ solution was added, and the solution was vortexed. The upper phase was transferred to the vial. $\mathrm{Na}_{2} \mathrm{SO}_{4}$ anhydrous was added to the vial to absorb the moisture. FAMEs from external standards or FAMEs resulting from sample derivatization were injected separately into a gas chromatography (GC) instrument. GC analyses were performed on a 7890A gas chromatography system (Agilent Technologies, Santa Clara, CA, USA), equipped with a flame ionization detector and a spitless injector $(1 \mu \mathrm{L})$. The injector and detector temperatures were set at $270{ }^{\circ} \mathrm{C}$ and $280^{\circ} \mathrm{C}$, respectively. The column used was a DB-23 $(60 \mathrm{~m} \times 0.25 \mathrm{~mm}$, with a film thickness of $0.25 \mu \mathrm{m}$ ). This column was purchased from J and W Scientific (Folsom, CA, USA). The GC oven program was: $130^{\circ} \mathrm{C}$ (hold $2 \mathrm{~min}$ ), $170{ }^{\circ} \mathrm{C}$ at $6.5^{\circ} \mathrm{C} / \mathrm{min}$ (hold for $5 \mathrm{~min}$ ), to $215^{\circ} \mathrm{C}$ at $2.75{ }^{\circ} \mathrm{C} / \mathrm{min}$ (hold for $12 \mathrm{~min}$ ), and $230^{\circ} \mathrm{C}$ at $30^{\circ} \mathrm{C} / \mathrm{min}$ (hold $30 \mathrm{~min}$ ). Ultrahigh purity helium and nitrogen were used as carrier gases at flow rates of 11.07 and $31.24 \mathrm{~mL} / \mathrm{min}$. Fatty acids were identified by comparing the retention times of the peaks with the respective external standards.

\subsubsection{Determination of DPPH Radical Scavenging Activity}

The antioxidant activity of the E. guineensis fruit extract was determined using the DPPH free radical scavenging activity method. The sample reacted with DPPH $(2,2-$ diphenyl-2-picrylhydrazy). When DPPH reacts with an antioxidant compound, it converts from violet to colorless DPPH-H. The samples were prepared at different concentrations in ethanol solution $(3.125-150 \mu \mathrm{g} / \mathrm{mL})$. The sample solution $(100 \mu \mathrm{L})$ reacted with $100 \mu \mathrm{L}$ of $0.06 \mathrm{mM}$ DPPH solution in ethanol and incubated for $30 \mathrm{~min}$ in the dark. The absorbance was measured at a wavelength of $517 \mathrm{~nm}$. Ascorbic acid was used as a positive control.

$$
\text { DPPH scavenging effect }(\%)=\frac{A_{\text {control }}-A_{\text {sample }}}{A_{\text {control }}} \times 100
$$

$A_{\text {control }}$ is the absorbance of DPPH solution without the extract. $A_{\text {sample }}$ is the absorbance of the extract that reacts with the $\mathrm{DPPH}$ solution. The $\mathrm{IC}_{50}$ value is the concentration required to inhibit $50 \%$ of the oxidation used to compare DPPH scavenging activity.

\subsection{Preparation of E. guineensis Fruit Extract Loaded SLNs}

First, an experimental design was used to optimize the blank SLN with varying amounts of glyceryl monostearate, Span ${ }^{\circledR}$ 80, and Tween ${ }^{\circledR}$ 80. The E. guineensis fruit extract was then loaded into the optimized SLN, as shown in Table 1. Preparation was performed using the hot homogenization method. The E. guineensis fruit extract and glyceryl monostearate were mixed and heated to $75{ }^{\circ} \mathrm{C}$ until a clear solution was obtained. Tween $^{\circledR} 80$ and Span ${ }^{\circledR} 80$ were dissolved in water until they were homogeneous. The surfactant solution was poured into the extract solution and blended with a homogenizer (IKA T18 Basic Ultra-Turrax ${ }^{\circledR}$, IKA, Staufen im Breisgau, Germany) at medium speed 
(18,000 rpm) for $15 \mathrm{~min}$, while continuously heating. Then, the beaker containing the mixture was transferred to an ice bath for $5 \mathrm{~min}$. The obtained SLNs were placed in a tight container until use.

Table 1. Composition of solid lipid nanoparticles.

\begin{tabular}{cc}
\hline Ingredients & Amount (\%) \\
\hline Elaeis guineensis fruit extract & 6.00 \\
Sorbitan monooleate (Span 80) & 1.12 \\
Polysorbate 80 (Tween 80) & 0.83 \\
Glyceryl monostearate & 0.30 \\
Purified water & 91.75 \\
Total weight & 100.00 \\
\hline
\end{tabular}

\subsection{Characterization of E. guineensis Fruit Extract Loaded SLNs}

\subsubsection{Physical Properties}

The appearance of SLNs loaded with the E. guineensis fruit extract was recorded for organoleptic characteristics (color, smell, and product clarity). The $\mathrm{pH}$ value was measured using a digital calibrated $\mathrm{pH}$ meter (SevenEasy ${ }^{\mathrm{TM}} \mathrm{pH}$, Mettler Toledo, Switzerland). The $\mathrm{pH}$ values were determined three times and reported as the mean \pm standard deviation.

\subsubsection{Measurement of Particle Size and Zeta Potential}

Particle size analysis of the SLNs was performed by dynamic light scattering (DLS), also known as photon correlation spectroscopy (PCS), using Zetasizer equipment (NanoZS ZEN 3600, Malvern Instruments Ltd., Worcestershire, UK). Before the measurements, formulations with and without E. guineensis fruit extract were diluted twice using ultrapurified water to yield an appropriate scattering intensity. The particle size measurements were performed at $25^{\circ} \mathrm{C}$. The particle size and polydispersity index (PI) of the investigated formulations were obtained by calculating the average of 10 measurements at an angle of $90^{\circ}$.

The zeta potential of the SLNs was determined by measuring the electrophoretic mobility using a Zetasizer (model Nano-ZS ZEN 3600, Malvern Instruments Ltd., Malvern, UK). All samples were diluted with ultra-purified water and the measurements were conducted at $25^{\circ} \mathrm{C}[28]$.

\subsubsection{Transmission Electron Microscopy (TEM)}

The morphology of E. guineensis fruit extract loaded SLN formulations was observed using TEM (1555VP FESEM, Zeiss, Jena, Germany). One drop of SLNs was diluted 50 times in purified water before being applied to a 400-mesh carbon film and copper grid and negatively stained with $1 \%$ phosphotungstic acid. Before the TEM inspection, the samples were air-dried [29].

\subsection{Preparation of Day and Night Creams Containing E. guineensis Fruit Extract Loaded SLN (Day and Night Creams)}

E. guineensis fruit extract loaded SLN was used as an active component in the day and night cream formulations, at a concentration of 50\%, which equaled E. guineensis fruit extract of $3 \%$ in the final formula. To adjust the formula to obtain a suitable cream, we optimized the suitable ingredients in both the oil and water phases during the development process. The optimized cream formulations comprised oil phase components such as liquid paraffin, white soft paraffin, isopropyl myristate, glyceryl monostearate, cetyl alcohol, and stearic acid. The water phase contained carbomer 940, glycerin, propylene glycol, and polysorbate 80. In addition, tocopherol acetate, disodium EDTA, and phenoxyethanol were chosen as the antioxidant, chelating agent, and preservative, respectively. Physical and chemical sun protective agents (titanium dioxide and octyl methoxycinnamate) were only 
added to the day cream. Grape seed extract was added to both formulations to increase the antioxidative activity of the products.

Day cream and night cream products were prepared by the hot homogenization method, using a high shear mixer and homogenizer. Glyceryl monostearate, liquid paraffin, white soft paraffin, isopropyl myristate, cetyl alcohol, stearic acid, and octyl methoxy cinnamate were dissolved together as an oil phase and heated to $70 \pm 2{ }^{\circ} \mathrm{C}$. The water phase included E. guineensis fruit extract loaded SLN as an active ingredient, which was dispersed with propylene glycol, glycerin, polysorbate 80, titanium dioxide, citric acid, phenoxyethanol, disodium EDTA, and water. Carbomer 940 was slowly dispersed with a small amount of glycerin and continuously dissolved in the water phase until a clear solution was obtained. Triethanolamine was added to form a clear gel solution. The obtained water phase was heated to $75 \pm 2{ }^{\circ} \mathrm{C}$. After heating, the cream was made by adding the water phase to the oil phase and continuously mixing for $10 \mathrm{~min}$ with a mechanical mixer. Finally, during this stirring period, tocopherol acetate and grape seed extract were added to the formulations, and the cream was homogenized using a tiny homogenizer at $3000 \mathrm{rpm}$ for $10 \mathrm{~min}$. The same procedure was used to prepare the night cream formulation, but without the sun protection ingredients, polysorbate 80 , glyceryl monostearate, or citric acid. The full list of the day and night cream formulations is shown in Table 2.

Table 2. Formulation of day and night creams containing E. guineensis fruit extract, loaded with solid lipid nanoparticles (day and night creams).

\begin{tabular}{|c|c|c|c|}
\hline \multirow{2}{*}{ Ingredients } & \multicolumn{2}{|c|}{ Amount (\% w/w) } & \multirow{2}{*}{ Function } \\
\hline & Day Cream & Night Cream & \\
\hline $\begin{array}{l}\text { E. guineensis fruit extract loaded } \\
\text { with solid lipid nanoparticles }\end{array}$ & 50.00 & 50.00 & Active ingredient \\
\hline Octyl methoxy cinnamate & 7.00 & - & Sunscreening agent \\
\hline Liquid paraffin & 5.00 & 10.00 & $\begin{array}{c}\text { Skin conditioning agent, } \\
\text { Emollient }\end{array}$ \\
\hline Propylene glycol & 5.00 & 5.00 & Humectant \\
\hline Glycerin & 5.00 & 5.00 & Humectant \\
\hline Glyceryl monostearate-SE & 4.40 & - & $\begin{array}{l}\text { Thickening agent, } \\
\text { Emulsifier }\end{array}$ \\
\hline White soft paraffin & 4.00 & 5.00 & $\begin{array}{c}\text { Skin conditioning agent, } \\
\text { Emollient }\end{array}$ \\
\hline Polysorbate 80 (Tween ${ }^{\circledR} 80$ ) & 3.60 & - & Emulsifier \\
\hline Isopropyl myristate & 3.00 & 3.00 & $\begin{array}{c}\text { Skin conditioning agent, } \\
\text { Emollient }\end{array}$ \\
\hline Cetyl alcohol & 3.00 & 5.00 & $\begin{array}{l}\text { Thickening agent, } \\
\text { Emollient }\end{array}$ \\
\hline Titanium dioxide & 3.00 & - & Sunscreening agent \\
\hline Stearic acid & 2.00 & 2.00 & $\begin{array}{l}\text { Thickening agent, } \\
\text { Emollient }\end{array}$ \\
\hline Grape seed extract & 1.00 & 1.00 & Antioxidant \\
\hline Phenoxyethanol & 0.50 & 0.50 & Preservative \\
\hline Tocopherol acetate & 0.50 & 0.50 & Antioxidant \\
\hline Carbomer 940 & 0.20 & 0.20 & Viscosity increasing agent \\
\hline Triethanolamine & 0.10 & 0.10 & Neutralizing carbomer \\
\hline Citric acid & 0.05 & - & $\mathrm{pH}$ adjustment \\
\hline Disodium EDTA & 0.005 & 0.005 & Chelating agent \\
\hline Purified water & 2.645 & 12.695 & Vehicle \\
\hline Total weight & 100.00 & 100.00 & \\
\hline
\end{tabular}

2.7. Evaluation of the Day and Night Creams

\subsubsection{Physical Properties}

The appearance of the day and night creams was recorded for the organoleptic properties color, smell, and product clarity. The $\mathrm{pH}$ value was measured using a digital calibrated 
pH meter (SevenEasy ${ }^{\mathrm{TM}} \mathrm{pH}$, Mettler Toledo, Switzerland). The $\mathrm{pH}$ values were determined three times and reported as the mean \pm standard deviation. The viscosity was measured using a rheometer (HAAKE MARS 60) equipped with a Peltier temperature control system (ThermoFisher Scientific, Karlsruhe, Germany).

\subsubsection{In Vitro Sun Protection Factor (SPF) Evaluation}

The photoprotective efficacy was assessed in vitro by determining the SPF value of the formulations, which was calculated using an SPF analyzer (Optometrics LLC/SPF-290F, Miami, FL, USA) and performed according to a previous study [30]. Each day cream and night cream were spread $\left(2 \mathrm{mg} / \mathrm{cm}^{2}\right)$ over a polymethyl methacrylate (PMMA) plate $\left(70.7 \mathrm{~mm}^{2}\right)$ using a fingertip. The plate samples were then dried for $15 \mathrm{~min}$, protected from light, and exposed to a xenon arc solar simulator. Measurements were made under the following laboratory conditions: $24.0 \pm 0.5^{\circ} \mathrm{C}$ and $50-60 \% \mathrm{RH}$. The measurement was performed by scanning nine spots on each sample at $2 \mathrm{~nm}$ interval between 290 and $400 \mathrm{~nm}$. The UVB protection efficacy was recorded as SPF. An intact, non-coated, PMMA plate was used as a blank reference, representing 100\% light transmission. All measurements were performed in triplicates.

\subsubsection{Stability Study}

The day and night creams were separately packaged in clear polyethylene (PE) plastic jar containers (50 g) and stored at a temperature of $30 \pm 0.5^{\circ} \mathrm{C}$ and a relative humidity of $75 \pm 5 \%$ for 6 months to determine the stability under actual storage conditions in Thailand (hot and humid zone). In addition, the accelerated stability study was performed by freeze-thaw cycling at $2-8{ }^{\circ} \mathrm{C}$ for $48 \mathrm{~h}$ and $45^{\circ} \mathrm{C}$ for $48 \mathrm{~h}$ and repeated for six cycles. The content of vitamin $\mathrm{E}, \beta$-carotene, and physical properties, including appearance, $\mathrm{pH}$, and viscosity, were recorded.

\subsection{Clinical Study of Safety and Skin Efficacy of the Day and Night Creams}

\subsubsection{Ethics Consideration}

The current study is a prospective, open-label, randomized clinical trial. The study protocol was approved by the Human Research Ethics Committee of Walailak University (WUEC-19-186-01) on 18 October 2019.

\subsubsection{Subjects}

All participants were female, aged 25-50 years, and lived in Nakhon Si Thammarat Province, Thailand. There are no similar clinical trials with E. guineensis oil extract. The clinical study of E. guineensis extract, as an anti-aging cream, reported in the literature was used to calculate the sample size, but it was not a similar study. The number of subjects used for skin efficacy testing in this study was determined as per Gaspar et al. [31], who studied the effect of skincare products on skin water content (stratum corneum water content and transepidermal water loss) and skin roughness in 14 human volunteers per group. In addition, Lademann et al. [32] studied the effect of skin creams on hydration and skin elasticity (stratum corneum and elasticity) by testing 15 volunteers per group. Therefore, we set the number of volunteers to a larger sample size of 35 participants. The inclusion and exclusion criteria are presented in Table 3. 
Table 3. Inclusion criteria and exclusion criteria.

- $\quad$ Healthy female participants aged 25-50 years, Thai nationality.

- $\quad$ Skin type II-V (categorized by melanin index).

- No history of allergy to chemicals or natural substances.

- No history of skin diseases such as eczema, ringworm, psoriasis, herpes zoster, skin cancer, that affect the study.

- $\quad$ No open wounds, blisters, and skin diseases at the test site.

- No other products used at the test site area (such as creams, lotions or serums). If they used any products, they should terminate for at least 2 weeks before the clinical trial and during the clinical trial study.

- No steroids, antihistamines, antibiotics and anti-inflammatory drugs were used for at least 2 weeks before and during the test.

- Not in the process of being a volunteer for another research.

- Able to follow up on the test results for a specified period of time.

- Participants wrote and signed a consent form to participate in the study.

- Women who are pregnant and lactating.

- Women with serious or chronic illnesses that may affect this clinical research.

- Women with dermatitis or allergic reactions at the test site during study participation. Women whose daily activities or hobbies are exposed to sunlight for more than $4 \mathrm{~h}$ a day. Women with skin irritation test results from products.

\subsubsection{Skin Irritation Protocol}

This test is used to determine whether the product used for testing causes irritation to the skin to confirm the safety of the products. A single-patch test protocol was used for the evaluation. General information of the participants who used facial cream products, either day or night creams, was recorded. The principal investigator described the information of the products and study methods to all volunteers. Each participant was tested with the two products (day and night creams) for the skin irritation study by applying $0.5 \mathrm{~g}$ of each cream separately into the aluminum well of the Finn chamber ${ }^{\circledR}$ occlusive patch. Each well was $0.8 \mathrm{~cm}$ in diameter or $0.5 \mathrm{~cm}^{2}$ in area. After cleaning the experimental area with $0.9 \%$ sodium chloride solution, the Finn chamber ${ }^{\circledR}$ occlusive patch containing the tested cream was applied to the forearm of the participants and covered with waterproof tape (Nexcare, $3 \mathrm{M}$, Thailand). After $48 \mathrm{~h}$ of application, the Finn chamber ${ }^{\circledR}$ was removed, and the surfacemounted product was wiped off the skin with a cotton swab moistened with $0.9 \%$ sodium chloride. The principal investigator or skin specialist observed and evaluated the skin reactions and recorded the relevant scores. Table 4 describes the severity of erythema and edema parameters used for evaluation in this study [33]. The participants verified the absence of a reaction $24 \mathrm{~h}$ after patch removal. The evaluation and interpretation of the results, obtained under the experimental conditions, was performed by calculating the mean irritation index (MII), as shown in Equation (2) and interpreted in Table 5 [33].

$$
\mathrm{MII}=\Sigma \text { of the grade erythema and edema/number of volunteers }
$$

Table 4. Clinical examination and scoring of skin irritation test.

\begin{tabular}{|c|c|c|c|}
\hline \multirow{2}{*}{ Score } & \multirow{2}{*}{ Assessment of Reaction } & \multicolumn{2}{|c|}{ Parameter Evaluated } \\
\hline & & Erythema (E) & Oedema (O) \\
\hline 0 & Absent & \multirow{2}{*}{$\begin{array}{c}\text { No erythema } \\
\text { Barely perceptible: like pink color of one } \\
\text { part of the tested area) }\end{array}$} & No oedema \\
\hline 0.5 & Doubtful & & Palpable, barely visible \\
\hline 1 & Slight & $\begin{array}{l}\text { Quiet pink color of the complete tested } \\
\text { area or rather visible on one part of the } \\
\text { tested area }\end{array}$ & Palpable, visible \\
\hline 2 & Obvious & $\begin{array}{c}\text { Obvious erythema covering the whole } \\
\text { tested area }\end{array}$ & $\begin{array}{l}\text { Obvious oedema (thickness }<1 \mathrm{~mm} \text { ) with or } \\
\text { without papule(s) or vesicle(s) }\end{array}$ \\
\hline 3 & Important & $\begin{array}{l}\text { Obvious erythema diffusing outside the } \\
\text { tested area }\end{array}$ & $\begin{array}{c}\text { Severe oedema (thickness } \geq 1 \mathrm{~mm} \text { or diffusing } \\
\text { outside the tested area) with or without } \\
\text { papule(s) or vesicle(s) }\end{array}$ \\
\hline
\end{tabular}


Table 5. Interpretation of Mean Irritation Index (M.I.I.).

\begin{tabular}{cc}
\hline Mean Irritation Index (M.I.I.) & Product Classification \\
\hline M.I.I. $=0.0$ & Non-Irritating (NI) / Very Good Cutaneous Compatibility \\
M.I.I. $<0.20$ & Non-Irritating (NI)/Good Cutaneous Compatibility \\
$0.20 \leq$ M.I.I. $<0.50$ & Slightly Irritating (SI)/Intermediate Cutaneous Compatibility \\
$0.50 \leq$ M.I.I. $<1$ & Moderately Irritating (NI)/Bad Cutaneous Compatibility \\
M.I.I. $>1$ & Irritating (I)/Very Bad Cutaneous Compatibility \\
\hline
\end{tabular}

\subsubsection{Clinical Efficacy Study Protocol}

After completing the skin irritation study and excluding the participants that did not compile the results, the participants were divided into two groups by computer randomization. Group 1 received $50 \mathrm{~g}$ of day cream packed in a PE plastic jar. Group 2 received a night cream with the same package. The principal investigator advised the instructions for the cream use. Briefly, after washing and wiping the face to dry, the cream was applied daily on the face in the morning for day cream or before bedtime for night cream users, for consecutive 30 days. The participants had to avoid applying other facial care products to their faces during the clinical study period. The participants in both groups were investigated five times. At the first meeting, the skin parameters of the participants were measured before applying the cream as the baseline value (1st measurement). The 2nd measurement was performed $30 \mathrm{~min}$ after the first application of the cream. The 3rd, 4th, and 5th measurements were performed after applying the cream for 7, 14, and 30 days, respectively. Before the measurements, the volunteers were housed in an air-conditioned room at $25 \pm 2{ }^{\circ} \mathrm{C}$ for $30 \mathrm{~min}$ to adjust their skin. Skin was measured in the same area every time. The skin condition measurement included the following five tests:

1. The stratum corneum water content and the amount of water accumulated in the epidermis were measured using Corneometer ${ }^{\circledR} \mathrm{CM} 852$ (Courage + Khazaka Electronic Co., Ltd., Köln, Germany).

2. TEWL or the amount of water lost from the skin was measured using Tewameter ${ }^{\circledR}$ TM 300 (Courage + Khazaka Electronic Co., Ltd., Germany).

3. The skin elasticity was measured using Cutometer ${ }^{\circledR}$ MAP 580 (Courage + Khazaka Electronic Co., Ltd., Germany).

4. The melanin index representing pigment amount and skin redness was measured using Mexameter ${ }^{\circledR}$ MX 18 (Courage + Khazaka Electronic Co., Ltd., Germany).

The skin was photographed with a DSLR camera (Nikon D70, Nikon Corp. Tokyo, Japan) and the depth of wrinkles on the skin was recorded with the Visioscan SV 600 (Courage + Khazaka Electronic Co., Ltd., Germany) on Day 1 before cream application and on Day 30 before skin measurement. Some volunteers were photographed with permission, and publications of those photographs do not identify the subjects and are already acknowledged. The subjects were photographed with the DSLR camera from the front, and either side, at an angle of $45^{\circ}$, without editing the picture program.

All experiments were performed at the left cheek (L), right cheek (R), and forehead $(\mathrm{N})$ of the participants. The experiments conducted throughout the clinical study are summarized in Figure 2.

\subsubsection{Satisfactory Survey by Questionnaires}

Besides the clinical study to evaluate the efficacy of the products, a satisfaction survey of the participants was conducted to confirm the improvement in moisture, elasticity, and skin color change. The questionnaire to survey the efficacy of the anti-aging day and night products were answered by the volunteers of the clinical efficacy study (35 participants per group). After completing the clinical study, the questionnaire was sent to the participants to gauge their satisfaction with the products. The questionnaire for satisfaction assessment of day and night creams was developed based on product appearance, performance, and how the user felt about the change in skin conditions when applied. The topic assessment 
details included color, texture, smell, skin performance improvement including hydration, radiance, firmness, reduction of wrinkles, and skin irritation. Satisfaction scores were divided into five levels, with a score of 5 indicating the highest, and a score of 1 indicating the lowest satisfaction level.

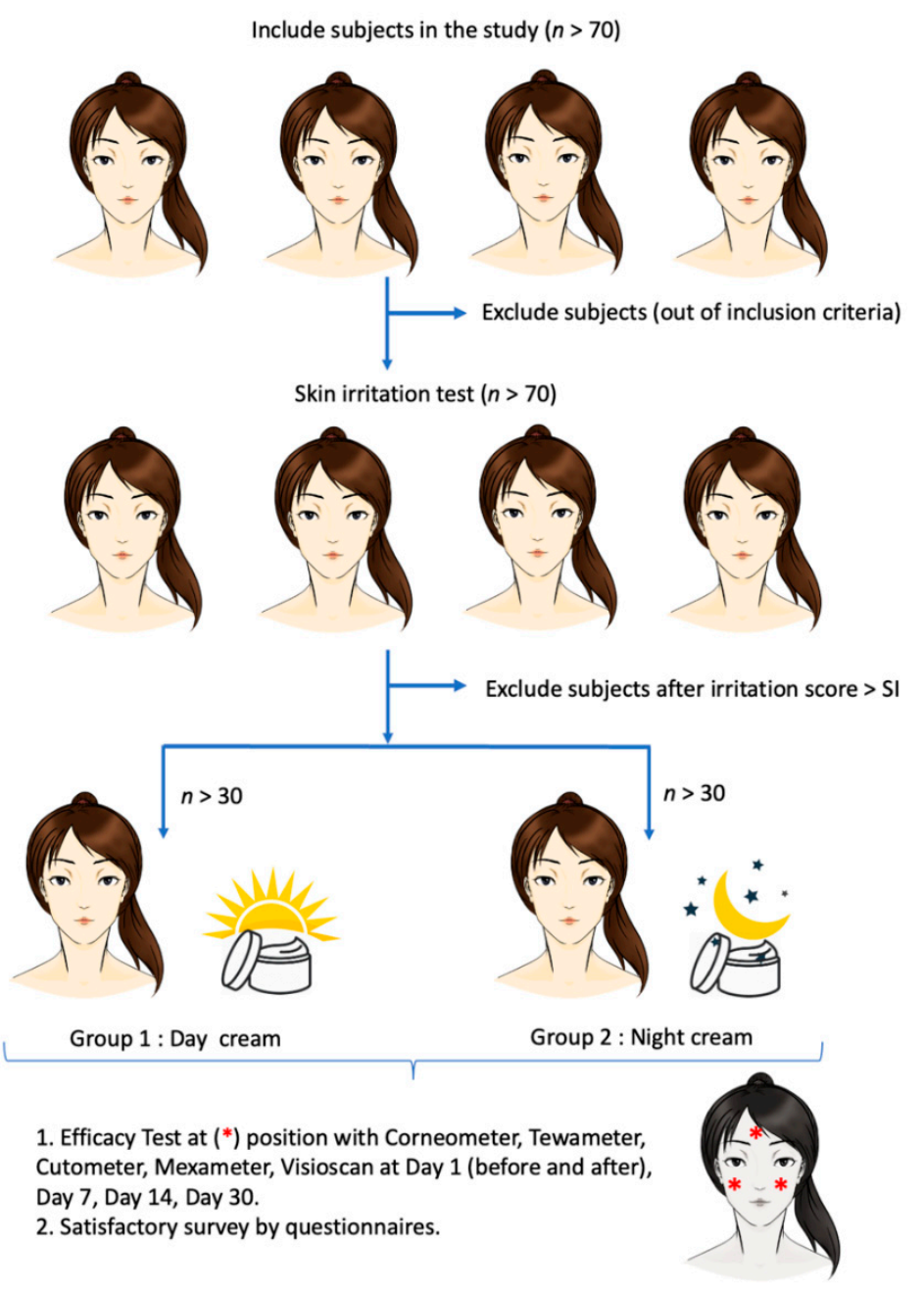

Figure 2. Schematic diagram of the clinical study of day and night creams containing red palm (Elaeis guineensis) fruit extract, loaded with solid lipid nanoparticles (day and night creams), in healthy volunteers.

\subsection{Statistical Analysis}

Paired $t$-test results were analyzed using the SPSS program (statistical significance level, $p<0.05$ ) to determine the results of skin improvement (before and after treatment). The results of the questionnaire were collected and analyzed by considering the mean and standard deviation. All data are presented as percentages. The difference in satisfaction, before and after using the product, was analyzed using paired $t$-tests at a $95 \%$ confidence level $(p<0.05)$.

\section{Results and Dissuasion}

\subsection{Extraction of E. guineensis Fruit}

An environmentally friendly cold extraction process was chosen for the extraction of E. guineensis, as it produces more active substances than other extraction methods [34]. The E. guineensis fruit extract, obtained from this process, is shown in Figure 3. 


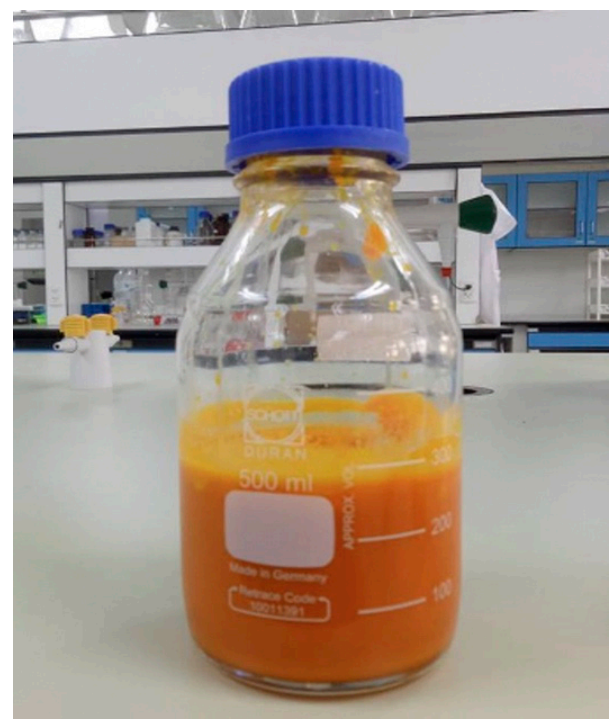

Figure 3. Photograph of the E. guineensis fruit extract from the cold extraction process.

The E. guineensis fruit extract appeared as a yellow-orange semi-solid substance. The extraction process gave a high percentage yield of $74.07 \% \pm 4.22 \%$ compared with the weight of the raw red palm fruits (after being cut into small pieces). The chemical and activity test results for the E. guineensis extract are shown in Table 6. The amount of fatty acids found in the extract was very small and included various types of fatty acids, such as caprylic acid (C8:0), capric acid (C10:0), lauric acid (C12:0), myristic acid (C14:0), palmitic acid (C6:0), and stearic acid (C18:0). The finished product specification for E. guineensis was determined, and is shown in Table 7, for quality control in the next extraction and for commercial batch production. The tocopherol and tocotrienol contents were combined in the specification as vitamin E content. Palmitic acid is the highest fatty acid found in $E$. guineensis fruit extract; therefore, it was added to the specification for quality control of $E$. guineensis fruit extract.

Table 6. Test results of E. guineensis fruit extract by cold extraction (mean \pm S.D., $n=3$ ).

\begin{tabular}{cc}
\hline Test & Results \\
\hline Appearance & Yellow to orange semi-solid or paste \\
$* \mathrm{IC}_{50}(\mu \mathrm{g} / \mathrm{mL})$ & $49.96 \pm 12$ \\
$* \mathrm{I} \mathrm{C}_{50}(\mu \mathrm{g} / \mathrm{mL})($ ascorbic acid as control) & $1.57 \pm 0.04$ \\
Tocopherol $(\mathrm{mg} / 100 \mathrm{~g})$ & $5.34 \pm 3.22$ \\
Tocotrienol $(\mathrm{mg} / 100 \mathrm{~g})$ & $4.23 \pm 0.15$ \\
$\beta$-Carotene $(\mathrm{mg} / 100 \mathrm{~g})$ & $21.89 \pm 0.23$ \\
Palmitic acid $(\mathrm{g} / 100 \mathrm{~g})$ & $74.53 \pm 0.68$ \\
Lauric acid $(\mathrm{g} / 100 \mathrm{~g})$ & $8.65 \pm 0.14$ \\
Stearic acid $(\mathrm{g} / 100 \mathrm{~g})$ & $6.48 \pm 0.76$ \\
Myristic acid $(\mathrm{g} / 100 \mathrm{~g})$ & $3.33 \pm 0.21$ \\
Caprylic acid $(\mathrm{g} / 100 \mathrm{~g})$ & $2.18 \pm 0.12$ \\
Capric acid $(\mathrm{g} / 100 \mathrm{~g})$ & $0.45 \pm 0.01$
\end{tabular}

${ }^{*} \mathrm{IC}_{50}(\mu \mathrm{g} / \mathrm{mL})$ determined by DPPH assay. Values are expressed as mean $\pm \mathrm{SD}$ of triplicate measurements.

Table 7. Finished product specification of E. guineensis fruit extract.

\begin{tabular}{cc}
\hline Attribute & Acceptance Criteria \\
\hline 1. Appearance & Yellow to orange semi-solid or paste \\
2. Vitamin A content $(\beta$-carotene $)$ & Not less than $3 \mathrm{mg} / 100 \mathrm{~g}$ \\
3. Total Vitamin E content & Not less than $1.5 \mathrm{mg} / 100 \mathrm{~g}$ \\
4. Palmitic acid $(\mathrm{C} 16: 0)$ & $30-85 \mathrm{~g} / 100 \mathrm{~g}$ \\
\hline
\end{tabular}




\subsection{Formulation Development of Creams Containing E. guineensis Fruit Extract Loaded Solid Lipid Nanoparticles}

The hot homogenization method was chosen for SLN preparation in this study because it is a reliable, simple, and reproducible method. Furthermore, it produced a uniform, homogeneous SLN dispersion without the problem of incomplete evaporation of organic solvents, as in the solvent evaporation method [35].

The E. guineensis fruit extract loaded SLNs were spherical, as shown in the TEM image (Figure 4). The encapsulation of E. guineensis fruit extract increased the particle size of blank SLN from $507.53 \pm 69.99$ to $609.70 \pm 54.48 \mathrm{~nm}$. The zeta potential of the free SLNs and E. guineensis fruit extract loaded SLNs are $-32.4 \pm 2.1 \mathrm{mV}$ and $-28.3 \pm 1.0 \mathrm{mV}$, respectively, as shown in Table 8 . Zeta potential is a key factor for evaluating the stability of colloidal dispersions [36]. Zeta potential values higher than $+30 \mathrm{mV}$, or lower than $-30 \mathrm{mV}$, are normally considered stable for colloidal formulations, as the particles are likely to be electrochemically stable under the investigated conditions. However, zeta potential values of, approximately, higher than $+20 \mathrm{mV}$ or lower than $-20 \mathrm{mV}$ are considered sufficient for nanoparticles whose stability results from a combination of electrostatic and steric stabilization [37]. As Table 8 demonstrates, as time passes, small increases are observed in the size and PI. The increase in size of blank SLNs kept at $4{ }^{\circ} \mathrm{C}$ and ambient temperature were about $6 \%$ and $11 \%$, respectively. In the similar way, E. guineensis fruit extract-loaded SLNs size increase were $2 \%$ and $5 \%$, respectively. Both blank and E. guineensis fruit extract loaded SLNs storage at $4{ }^{\circ} \mathrm{C}$ are more stable, in terms of size and polydispersity index, compared to at room temperature, as smaller changes in these parameters were observed. These results may be due to the kinetic energy of the system increasing as temperature increases, leading to more collision and aggregation of the particles [38]. Therefore, these SLNs should be kept at $4{ }^{\circ} \mathrm{C}$ prior to incorporation in the cream bases for acceptable stability. The zeta potential values of blank SLN and E. guineensis fruit extract loaded SLNs after 1 month storage are unchanged, reflecting that these SLN systems are physically stable.

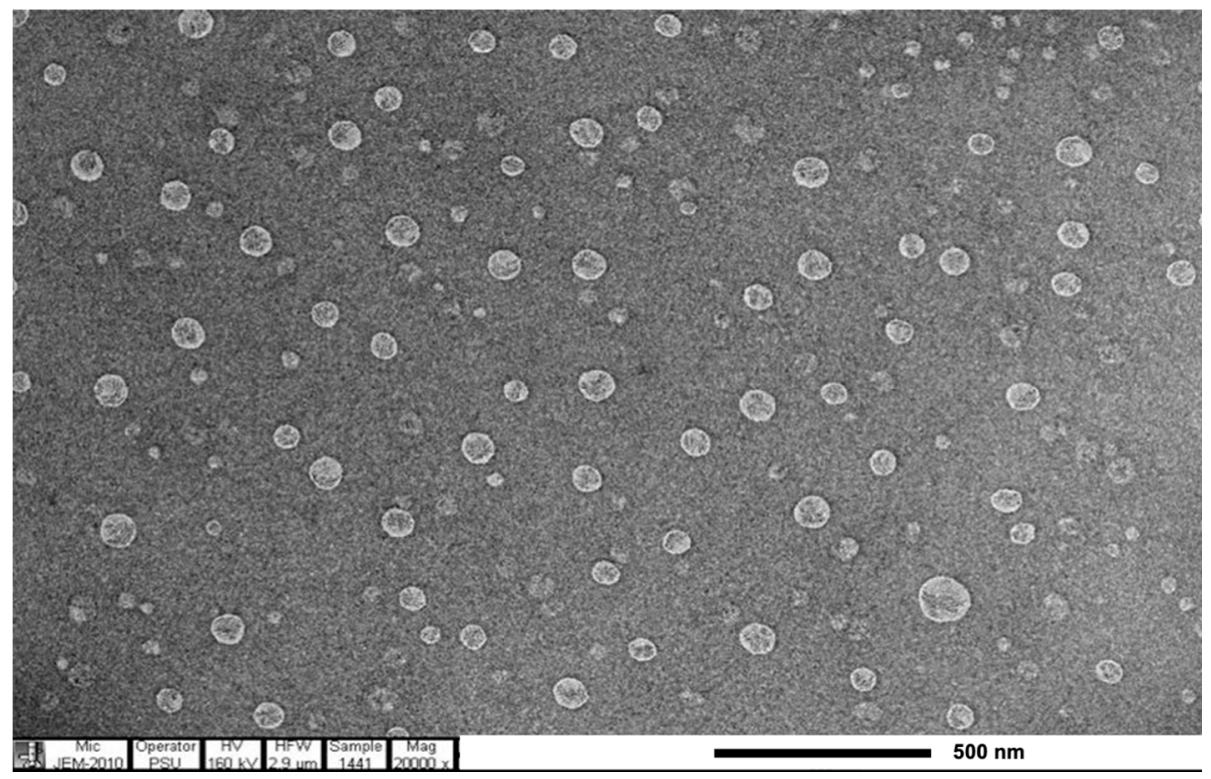

Figure 4. TEM image of E. guineensis fruit extract loaded solid lipid nanoparticles. 
Table 8. Physical properties results and stability of blank and E. guineensis fruit extract loaded solid lipid nanoparticles. Values are expressed as mean \pm SD of triplicate measurements.

\begin{tabular}{|c|c|c|c|c|}
\hline \multirow[b]{2}{*}{ Products } & \multirow{2}{*}{ Test } & \multicolumn{3}{|c|}{ Storage Conditions } \\
\hline & & Initial & $\begin{array}{c}4^{\circ} \mathrm{C} \\
\text { (1 Month) }\end{array}$ & $\begin{array}{c}\text { Ambient } \\
\text { (1 Month) }\end{array}$ \\
\hline \multirow{2}{*}{$\begin{array}{c}\text { Blank solid } \\
\text { lipid } \\
\text { nanoparticles }\end{array}$} & Appearance & & 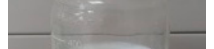 & \\
\hline & $\begin{array}{c}\mathrm{pH} \\
\text { Size }(\mathrm{nm}) \\
\text { Polydispersity index } \\
\text { Zeta potential }(\mathrm{mV})\end{array}$ & $\begin{array}{c}4.75 \pm 0.02 \\
507.53 \pm 69.99 \\
0.18 \\
-32.4 \pm 2.1\end{array}$ & $\begin{array}{c}4.76 \pm 0.02 \\
537.67 \pm 36.01 \\
0.24 \\
-30.6 \pm 2.8\end{array}$ & $\begin{array}{c}4.73 \pm 0.01 \\
561.47 \pm 36.66 \\
0.32 \\
-31.9 \pm 1.9\end{array}$ \\
\hline \multirow[t]{2}{*}{$\begin{array}{c}\text { E. guineensis } \\
\text { fruit extract } \\
\text { loaded solid } \\
\text { lipid } \\
\text { nanoparticles }\end{array}$} & Appearance & . & - & \\
\hline & $\begin{array}{c}\mathrm{pH} \\
\text { Size }(\mathrm{nm}) \\
\text { Polydispersity index } \\
\text { Zeta potential }(\mathrm{mV})\end{array}$ & $\begin{array}{c}4.77 \pm 0.01 \\
609.70 \pm 54.48 \\
0.22 \\
-28.3 \pm 1.0 \\
\end{array}$ & $\begin{array}{c}4.82 \pm 0.01 \\
619.53 \pm 22.42 \\
0.32 \\
-27.1 \pm 1.4 \\
\end{array}$ & $\begin{array}{c}4.90 \pm 0.01 \\
640.11 \pm 26.12 \\
0.40 \\
-28.1 \pm 1.1 \\
\end{array}$ \\
\hline
\end{tabular}

Glyceryl monostearate, polysorbate 80 , and sorbitan monooleate were used as SLN compositions aimed at increasing the permeation of active compounds through the skin to achieve hydration and anti-aging activity [39]. The E. guineensis fruit extract loaded SLN was added in the day and night creams as $50 \%$ of the formula, thus E. guineensis fruit extract formed $3 \%$ of the final formula. The developed cream is shown in Figure 5A,B. The color of the night cream appears more yellowish than the day cream because of the opacifying properties of titanium dioxide in the day cream. The physicochemical properties of the developed creams are presented in Table 9 (initial column). The $\mathrm{pH}$ of both formulations was between 4.7 and 5.75, which is suitable for face skincare [40]. The high viscosity of the night cream was the intention of the researcher to obtain a concentrated product suitable for use at night.

\subsection{Stability Study}

The results of the accelerated and long-term stability of the day and night creams are shown in Table 9. They were analyzed after six freeze-thaw cycles $\left(4\right.$ and $\left.40{ }^{\circ} \mathrm{C}\right)$ and at $30{ }^{\circ} \mathrm{C}$ and $75 \%$ relative humidity for 6 months of storage. These values were not different from the initial analysis in terms of $\mathrm{pH}$ and viscosity (within the range of $\pm 3 \%$ of the initial assay). The creams were stable and met the finished product specifications. There were no changes in the color, smell, or texture of the products. The appearance of the day and night creams after freeze-thaw is shown in Figure 5D,E. The contents of tocopherol, tocotrienol, and $\beta$-carotene were acceptable (within the finished product specification). Therefore, the products, including day and night creams, exhibited good stability in the PE jar. As the SLNs were incorporated in the bases of the day and night creams, their particle size and zeta potential, after incorporation, and stability after storage could not be determined because of the technical difficulty of separating the SLNs from the cream bases. Therefore, 
in this study, only the appearance, content of active constituents, $\mathrm{pH}$, and viscosity were investigated as stability parameters.
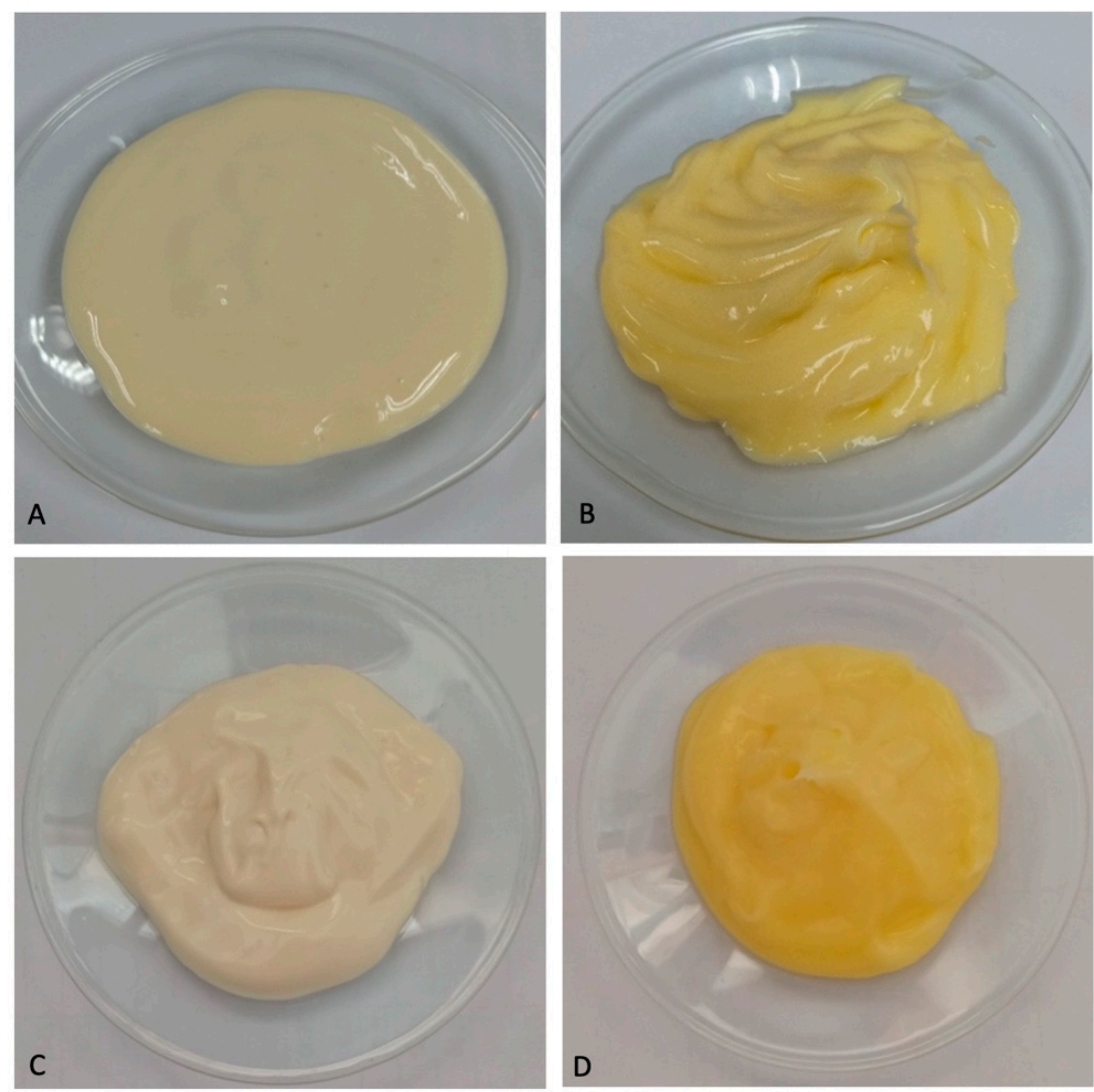

Figure 5. Photographs of day and night creams containing E. guineensis fruit extract loaded solid lipid nanoparticles: freshly prepared day cream (A), freshly prepared night cream (B), day cream after freeze-thaw 6 cycles (C), night cream after freeze-thaw 6 cycles (D).

Table 9. Test stability results of day and night cream, containing E. guineensis fruit extract loaded solid lipid nanoparticles (day and night creams). Values are expressed as mean $\pm \mathrm{SD}$ of triplicate measurements.

\begin{tabular}{|c|c|c|c|c|}
\hline \multirow[b]{2}{*}{ Products } & \multirow{2}{*}{ Test } & \multicolumn{3}{|c|}{ Storage Conditions } \\
\hline & & Initial & $\begin{array}{l}\text { Freeze-Thaw } \\
\text { (6 Cycles) }\end{array}$ & $\begin{array}{c}30{ }^{\circ} \mathrm{C} / 75 \% \mathrm{RH} \\
\text { (6 Months) }\end{array}$ \\
\hline \multirow{7}{*}{ Day cream } & Appearance & \multirow{7}{*}{$\begin{array}{l}\text { Light yellow smooth cream with } \\
\text { characteristic odor. } \\
5.72 \pm 0.02 \\
55,406.67 \pm 480.87 \\
15.32 \pm 0.77 \\
0.18 \pm 0.01 \\
0.14 \pm 0.04 \\
0.60 \pm 0.05\end{array}$} & Conform & Conform \\
\hline & $\mathrm{pH}$ & & $5.82 \pm 0.01$ & $5.71 \pm 0.03$ \\
\hline & Viscosity (mPaS) & & $80,663.33 \pm 461.99$ & $63,549.18 \pm 412.55$ \\
\hline & SPF value & & $14.57 \pm 0.33$ & $15.02 \pm 0.10$ \\
\hline & Tocopherol (mg/100 g) & & $0.21 \pm 0.02$ & $0.17 \pm 0.01$ \\
\hline & Tocotrienol (mg/100 g) & & $0.12 \pm 0.02$ & $0.15 \pm 0.01$ \\
\hline & $\beta$-Carotene (mg/100 g) & & $0.71 \pm 0.01$ & $0.63 \pm 0.03$ \\
\hline \multirow{6}{*}{ Night cream } & Appearance & \multirow{6}{*}{$\begin{array}{l}\text { Light yellow to yellow smooth } \\
\text { cream with characteristic odor. } \\
5.06 \pm 0.01 \\
843,600.00 \pm 23,618.43 \\
0.22 \pm 0.01 \\
0.15 \pm 0.02 \\
0.68 \pm 0.02\end{array}$} & Conform & Conform \\
\hline & $\mathrm{pH}$ & & $4.60 \pm 0.02$ & $5.12 \pm 0.02$ \\
\hline & Viscosity (mPaS) & & $366,933.33 \pm 17,778.73$ & $674,129.02 \pm 16,220.12$ \\
\hline & Tocopherol (mg/100 g) & & $0.22 \pm 0.02$ & $0.19 \pm 0.01$ \\
\hline & Tocotrienol (mg/100 g) & & $0.16 \pm 0.01$ & $0.12 \pm 0.02$ \\
\hline & $\beta$-Carotene (mg/100 g) & & $0.66 \pm 0.03$ & $0.60 \pm 0.01$ \\
\hline
\end{tabular}

\subsection{Skin Irritation Study of Day and Night Creams}

The active ingredients of the day and night creams included E. guineensis fruit extract, enriched with tocopherol, tocotrienol, and $\beta$-carotene, which showed antioxidant activ- 
ity [41]. A clinical study was conducted on volunteers to determine the anti-aging efficacy of the day and night creams. A total of 71 subjects, who participated in the irritation test, were enrolled in the study. Demographic characteristics of the volunteers are shown in Table 10. After $48 \mathrm{~h}$ of the irritation test, skin changes were assessed. It was found that all 71 participants did not develop redness or erythema, skin swelling, blisters, or pustules (edema) after $48 \mathrm{~h}$ of exposure to either product. The erythema score and the edema score were 0 for both products. However, one volunteer developed a small area of red skin at the night cream application site (erythema score $=1$ and edema score $=1$ ) approximately $24 \mathrm{~h}$ after patch removal. However, the skin reaction occurred at the waterproof plaster patch outside the aluminum well of the Finn chamber ${ }^{\circledR}$. To ensure the safety of this participant, she was excluded from the clinical efficacy study in the next step. With respect to percentage of irritation or abnormalities on the volunteers' skin, the day and night creams did not cause any irritation. The calculated MII of the day cream after the $48 \mathrm{~h}$ patch test and $24 \mathrm{~h}$ after patch removal was 0.00 . The MII value of the night cream was 0.00 after the $48 \mathrm{~h}$ patch test, and it was $0.02824 \mathrm{~h}$ after patch removal $(n=1)$. The MII results indicated that both day and night facial creams were non-irritating (NI) or had good cutaneous compatibility [33]. Both products can be applied safely to the skin because their ingredients are safe for use in cosmetics [42]. Although the night cream had a higher incidence of irritation than the day one, it was still considered a safe product based on its MII result.

Table 10. Demographic characteristics information of the volunteers who used facial day and night creams containing E. guineensis fruit extract loaded solid lipid nanoparticles (day and night creams).

\begin{tabular}{ccc}
\hline Characteristics & Day Cream & Night Cream \\
\hline Total participants (n) & 34 & 34 \\
Gender & Female & Female \\
Nationality & Thai & Thai \\
Age range (years) & $25-50$ & $25-50$ \\
History of allergy to chemicals or substances from nature (n) & None & None \\
History of skin disease & None & None \\
The appearance of open wounds, blisters and skin lesions at & None & None \\
the test site was found (n) & & \\
\hline
\end{tabular}

\subsection{Clinical Efficacy by Skin Assessment}

The volunteers participating in the clinical efficacy study were the same as in the skin irritation study (35 participants per group). However, one volunteer per group did not show up for clinical study appointments, so the participants remained 34 persons per group. The cumulative water content in the epidermis or stratum corneum was measured using Corneometer ${ }^{\circledR}$ CM 825. After 30 days of application of the day and night creams, the accumulation of water content in the subject's epidermis significantly increased by $8.73 \% \pm 2.05 \%$ and $3.54 \% \pm 1.85 \%$, respectively, compared to the first use on Day 1 . The first application of the day and night creams showed a significant increase in water content up to $19.05 \% \pm 1.70 \%$ and $4.79 \% \pm 2.11 \%$, respectively, compared to the baseline. This indicated that the day and night creams have high efficacy in increasing the water content of the skin. In addition, the skin of all volunteers had an average dermal water content between 53.57 and 109.24 A.U. A value greater than 45 AU indicates that the skin is adequately hydrated [43]. The mean values of stratum corneum water content are shown in Figure 6A. 
A.

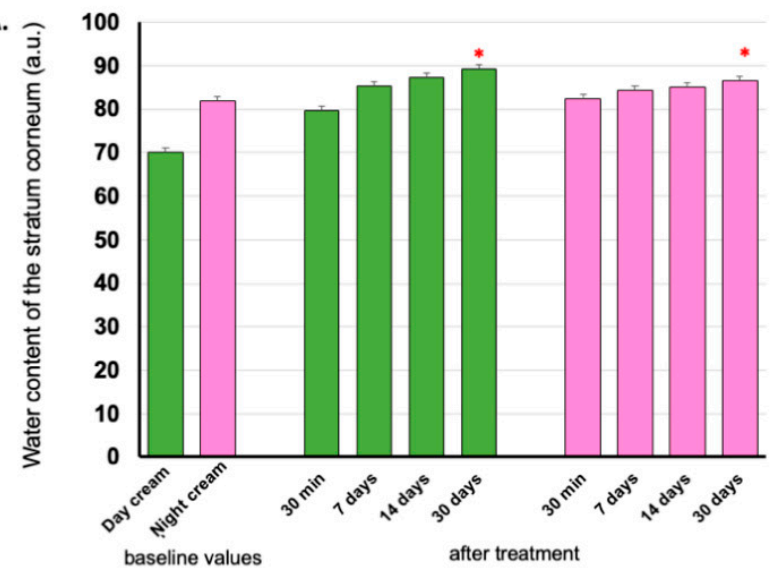

c.

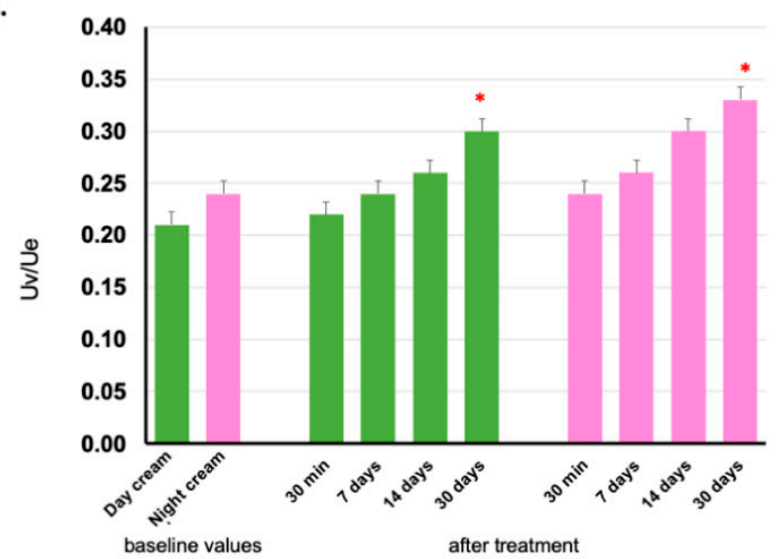

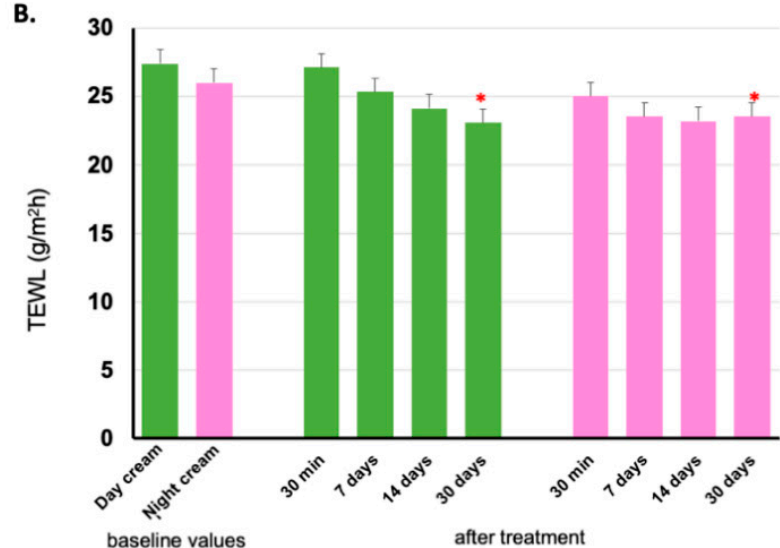

D.

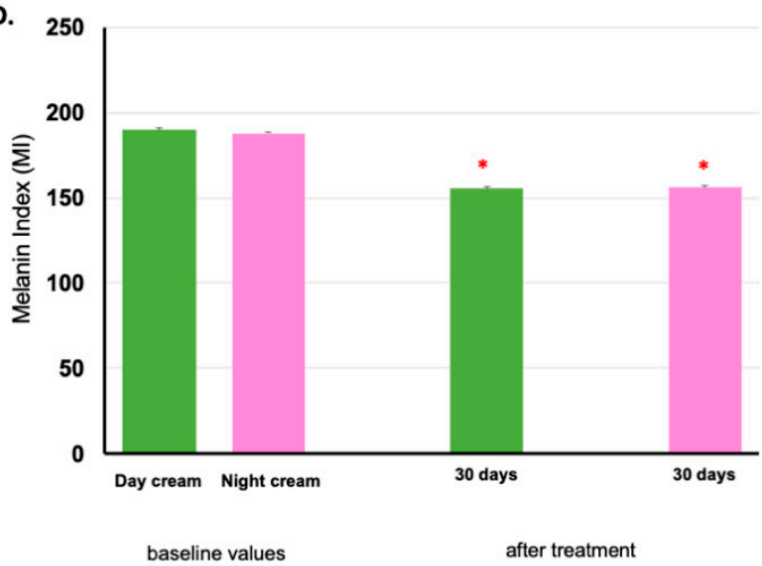

Figure 6. Stratum corneum water content (A), transepidermal water loss (TEWL) (B), cutaneous elasticity (C), melanin index (D) on volunteers' facial skin before application (baseline values) and after 30 min, 7 days, 14 days, and 30 days application of day and night creams containing E. guineensis fruit extract loaded solid lipid nanoparticles (day and night creams). The green bar represents the Day cream and the pink one represents the Night cream results. Significantly different when compared between baseline values $\left(^{*}\right)(p<0.05)$.

TEWL was measured using Tewameter ${ }^{\circledR}$ TM 300 in 34 subjects from each group using the day and night creams. The mean water loss from the skin of the subjects in the two groups decreased after 7,14 , and 30 days of cream application, compared to the baseline values. If the water loss from the skin is between 10 and $25 \mathrm{~g} / \mathrm{h} / \mathrm{m}^{2}$, the skin is healthy because there is little evaporation of water from the skin, which allows the skin to retain adequate moisture [44]. The TEWL values are shown in Figure 6B. From these results, day and night creams were found to decrease water loss from the skin epidermis, after application for 7 days, and increased after 14 and 30 days with statistical difference $(p<0.05)$.

The day cream seems to slightly increase the water content and reduce water loss from the skin epidermis compared to the night cream. However, both day and night creams improved skin health with a statistically significant difference $(p<0.05)$ after application for 30 days, compared with baseline values. This is likely the result of various components in the formulations containing the important active substances from red palm fruit extracts, such as tocopherol, tocotrienol, $\beta$-carotene, several fatty acids, and other moisturizing agents, in the cream formula, which acts as a barrier to protect the skin from losing water. Thus, the skin remained moist and healthy.

Skin elasticity is one of the key qualities that helps the skin appear young and healthy [45]. Skin elasticity can be assessed with the Cutometer ${ }^{\circledR}$ MPA 580, which measures the elasticity of the epidermis using suction pressure to mechanically deform the skin. The 
probe aperture of Cutometer ${ }^{\circledR}$ was sucked onto the skin for a while, and when the force was withdrawn, the skin would try to return to its original state. This value indicated the elasticity of the epidermis. The skin elasticity of the volunteers applying the day and night creams for 30 days significantly increased to $45.25 \pm 9.14 \%$ and $45.52 \pm 10.97 \%$, respectively, as shown in Figure 6C. The facial creams containing E. guineensis fruit extract loaded SLNs that contained active substances such as tocopherol, tocotrienol, $\beta$-carotene, and fatty acid, and the process of preparing creams with SLN technology allowed substances to be absorbed and permeated into the skin cells quickly. Antioxidant-rich formulations improve skin radiance and enhance skin elasticity in women [46].

The difference in skin color between individuals results from genetic diversity, depending on the amount of melanin and hemoglobin [47]. Skin color can be assessed using a Mexameter ${ }^{\circledR}$ MX 18 probe, which measures the melanin index. For the 34 volunteers applying the day and night creams, the average value of melanin pigment decreased in both experimental groups, indicating that both skin creams could increase the radiance of the skin. The night cream resulted in reduced melanin less than that of the day cream, on average, $18.29 \pm 4.12$ and $16.18 \pm 3.83 \%$, respectively, as shown in Figure 6D. Likely because of the sunscreen in the day cream. The reduction in melanin was caused by the physical and chemical sunscreens in the day cream. The reduction in melanin pigment results from important antioxidants such as tocopherol, tocotrienol, and $\beta$-carotene. Antioxidants inhibit the process of oxidation and melanogenesis of melanin pigment formation, so they help the skin appear bright and clear [48].

Photographs of the skin texture of volunteers, applying the day and night creams obtained by Visioscan VC98, are shown in Figure 7A,B, respectively. The subjects were photographed before the application of cream (Day 0), and after 7, 14, and 30 days from top to bottom. From the figure, it can be seen that the volunteers had smoother and more hydrated skin, and deep grooves in the skin looked shallower when compared to the images before using the day and night products.

In addition, the DSLR photos of the volunteers applying day or night creams are shown in Figure 8A-D. It can be seen that the volunteers had brighter skin, and dark spots were reduced when compared to the images before applying the facial creams.

\subsection{Satisfaction Survey of the Participants}

After completing the clinical efficacy experiment, 68 volunteers, comprising 34 subjects per group, answered the satisfaction questionnaires. The topics to gauge the satisfaction with the creams were color, smell, texture, surface spreadability, stickiness, and skin absorption of the creams. The satisfaction assessment was divided into five levels. Level 1 was very dissatisfied, and level 5 was very satisfied. The results of the overall satisfaction of the day and night creams were $4.05 \pm 0.53$ and $4.56 \pm 0.71$, respectively. These scores indicate the creams are pleasant to use and acceptable to consumers. Overall score evaluations by questionnaires were over 4.00, except that the stickiness of the day cream was $3.86 \pm 0.85$ because titanium dioxide, used as a physical sunscreen, made the cream viscous. The assessment of product efficacy by satisfaction score, including skin hydration, skin smoothness, skin radiance, skin firmness, reduction in wrinkles, and overall product performance, was gauged by the volunteers. All subjects' assessed satisfaction scores were $4.32 \pm 0.67$ and $4.62 \pm 0.49$ for the 30 days trial of the day and night creams, respectively (Figure 9). The volunteers were satisfied with the products at the highest level in terms of skin moisture, skin smoothness, radiance, and firmness of the skin. The volunteers were satisfied with the product in the moderate to high range, in terms of reduction in wrinkles in the day cream, but were highly satisfied with the night cream. In all subjects assessed, the overall product efficacy of both day and night facial creams was very satisfying to the consumers. 

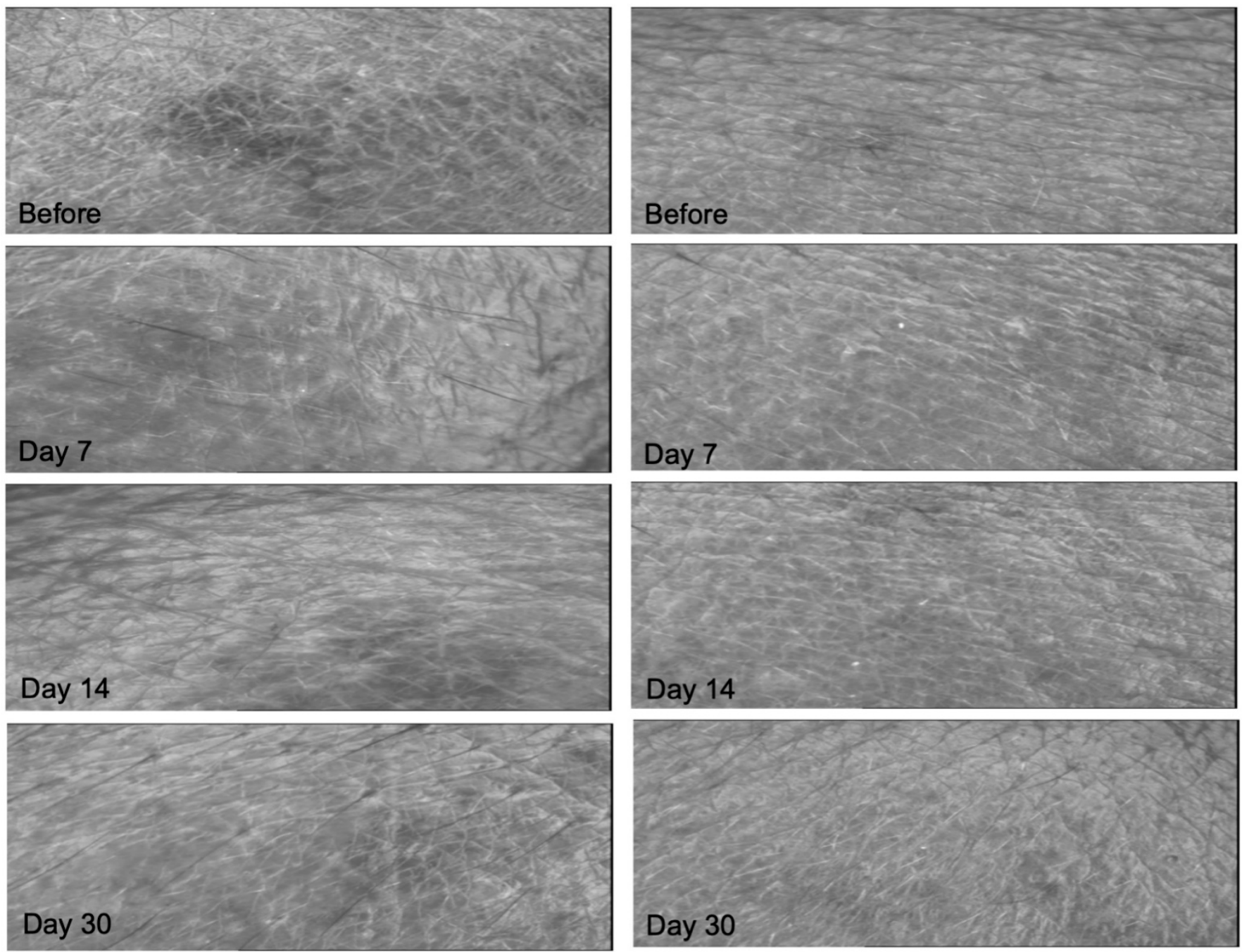

\section{A. Treatment with day cream}

B. Treatment with night cream

Figure 7. Skin surface evaluation by Visioscan VC98 of the subject who applied day (A) and night (B) creams containing E. guineensis fruit extract loaded solid lipid nanoparticles at Day 0, Day 7, Day 14, and Day 30 from top to bottom, respectively. 


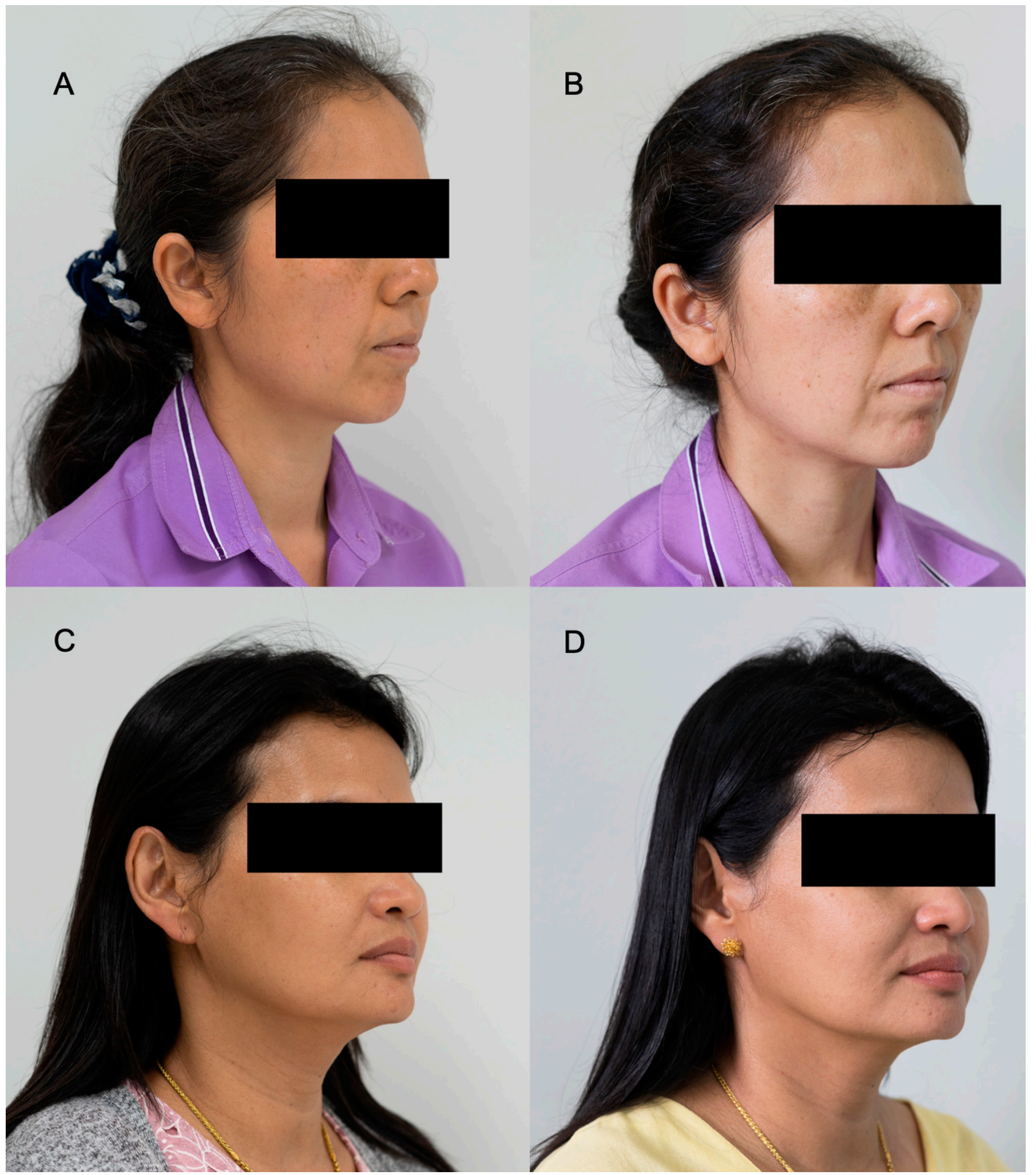

Figure 8. Examples of DSLR photographs from the subject volunteers treated with day and night creams, containing E. guineensis fruit extract loaded solid lipid nanoparticles, before treatment at Day $0(\mathbf{A}, \mathbf{C})$ and after treatment at Day $30(\mathbf{B}, \mathbf{D})$. 

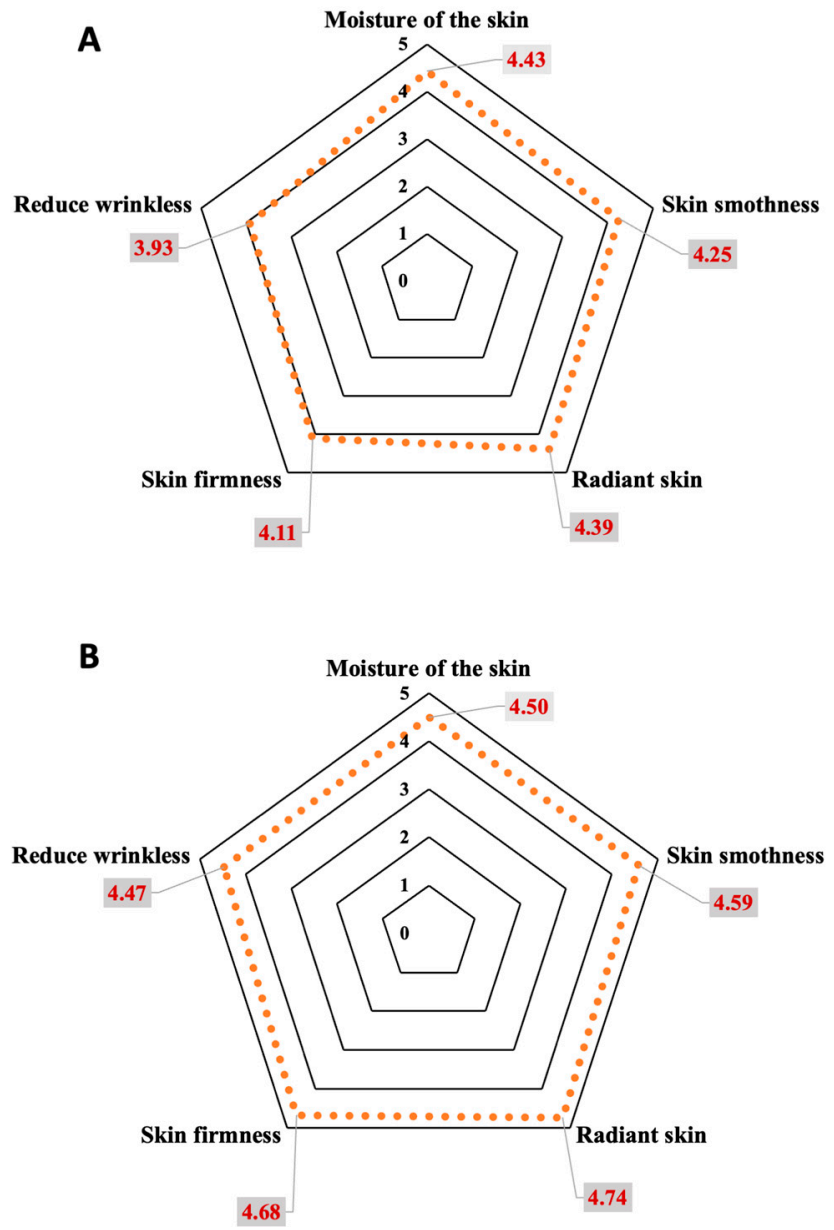

Figure 9. Volunteer satisfaction scores, after 30 days of treatment, with day (A) and night (B) creams containing E. guineensis fruit extract loaded solid lipid nanoparticles (day and night creams).

\section{Conclusions}

Crude palm fruit extract contains several ingredients for maintaining healthy skin, such as fatty acids, vitamin A, and vitamin E. Due to some constituents or impurities, crude palm is unsuitable as a cosmetic ingredient and for consumption. Therefore, the extraction process plays an important role in developing products. Cold extraction was used to obtain pure and high yields of the active compounds. This study successfully developed day and night cosmetic products containing 50\% SLNs loaded with E. guineensis fruit extract for the elderly. Day and night creams were stable under freeze-thaw and long-term conditions. The efficacy study of the developed creams was conducted in 68 Thai female volunteers, aged 25-50 years. The products did not cause irritation in the volunteers, with an incidence of $0 \%$ for day cream and $1.41 \%$ for the night cream. These results indicate the products were safe. The facial skin efficacy of the cream was evaluated for 30 days compared with the baseline values. The water accumulated in the epidermis layer, after applying the day and night creams, significantly increased by $8.73 \%$ and $5.34 \%$, respectively. The water lost from the skin decreased by $14.77 \%$ and $9.08 \%$ after using the day and night creams, respectively. Skin elasticity increased by $45 \%$ when applying the day or night creams. The skin melanin content, after using the day and night creams, was found to decrease between 15 and $17 \%$ and 17 and 20\%, respectively. The satisfaction assessment of the volunteers on the overall product efficacy of the day and night formulas were $4.32 \pm 0.67$ and $4.62 \pm 0.49$, respectively, which were in the high satisfaction range. In conclusion, day and night creams containing E. guineensis extract loaded SLNs are promising candidates for use as cosmeceutical products for healthy skin improvement. 


\begin{abstract}
Author Contributions: Conceptualization, A.A., A.S.Y., N.S., P.S., T.P. and S.S.; methodology, A.A., A.S.Y., N.S., P.S., T.P. and S.S.; validation, A.A.; formal analysis, A.A., A.S.Y., N.S., P.S., T.P. and S.S.; investigation, A.S.Y., N.S., P.S. and T.P.; writing-original draft preparation, S.S., P.S. and T.P.; writingreview and editing, A.A., A.S.Y., N.S., P.S., T.P. and S.S.; supervision, S.S.; project administration, S.S.; funding acquisition, S.S. All authors have read and agreed to the published version of the manuscript.
\end{abstract}

Funding: This research was funded by Sopitpattana Co., Ltd., 6, A-Group, Ratchadapisek Road, Ladyao, Chatuchak, Bangkok, 10900, Thailand. This research was financially supported by the new strategic research project (P2P), Walailak University, Thailand.

Institutional Review Board Statement: The study was conducted according to the guidelines of the Declaration of Helsinki and approved by the Human Research Ethics Committee of Walailak University, protocol code WUEC-19-186-01 on 18 October 2019).

Informed Consent Statement: Informed consent was obtained from all subjects involved in the study. Written informed consent has been obtained from the participants to publish this paper.

Data Availability Statement: The data presented in this study are available on reasonable request from the corresponding author.

Acknowledgments: This research was financially supported by the new strategic research project (P2P), Walailak University, Thailand. The authors would like to thank Pramote Cheewasopit who provided palm fruit (Elaeis guineensis) and also thanks to the Drug and Cosmetics Excellence Center, Walailak University, Thasala, Nakhon Si Thammarat, Thailand, for providing all research facilities.

Conflicts of Interest: The authors declare no conflict of interest.

\title{
References
}

1. Mesa-Arango, A.C.; Flórez-Munoz, S.V.; Sanclemente, G. Mechanism of skin aging. Iatreia 2017, 30, 160-170. [CrossRef]

2. Letsiou, S. Tracing skin aging process: A mini-review of in vitro approaches. Biogerontology 2021, 22, 261-272. [CrossRef]

3. Sarkar, R.; Podder, I.; Gokhale, N.; Jagadeesan, S.; Garf, V.K. Use of vegetable oils in dermatology: An overview. Int. J. Dermatol. 2017, 56, 1080-1086. [CrossRef]

4. Leow, S.; Fairus, S.; Sambanthamurthi, R. Water-soluble palm fruit extract: Composition, biological properties, and molecular mechanisms for health and non-health applications. Crit. Rev. Food Sci. Nutr. 2021, in press. [CrossRef] [PubMed]

5. Lademann, J.; Schanzer, S.; Meinke, M.; Sterry, W.; Darvin, M.E. Interaction between carotenoids and free radicals in human skin. Skin Pharmacol. Physiol. 2011, 24, 238-244. [CrossRef] [PubMed]

6. Osuala, N.; Ezechukwu, L.A.; Tony, P.O. Screening of wound healing effect of Elaeis guineensis Oil, extract of Vernonia amygdalina mixed with dried egg albumin on burn wound inflicted guinea pig. World J. Biol. Pharm. Health Sci. 2021, 8, 13-28. [CrossRef]

7. Imoisi, O.; Ilori, G.; Agho, I.; Ekhator, J. Palm oil, its nutritional and health implications (review). J. Appl. Sci. Environ. Manag. 2015, 19, 127-133. [CrossRef]

8. Tan, C.H.; Lee, C.J.; Tan, S.N.; Poon, D.T.S.; Chong, C.Y.E.; Pui, L.P. Red palm oil; a review on processing, health benefits and its application in food. J. Oleo Sci. 2021, 70, 1201-1210. [CrossRef]

9. Owoyele, B.V.; Owolabi, G.O. Traditional oil palm (Elaeis guineensis jacq.) and its medicinal uses: A review. Tang Humanit. Med. 2014, 4, e16. [CrossRef]

10. Ramli, S.; Norhman, N.; Zainuddin, N.; Ja'afar, S.M.; Rahman, I.A. Nanoemulsion based palm olein as vitamin E carrier. Malays. J. Anal. Sci. 2017, 21, 1399-1408.

11. Mahdi, E.S.; Noor, A.M.; Sakeena, M.H.; Abdullah, G.; Abdulkarim, M.F.; Sattar, M.A. Formulation and in vitro release evaluation of newly synthesized palm kernel oil esters-based nanoemulsion delivery system for $30 \%$ ethanolic dried extract derived from local Phyllanthus urinaria for skin antiaging. Int. J. Nanomed. 2011, 6, 2499-2512. [CrossRef] [PubMed]

12. Ilomuanya, M.O.; Oforkaja, C.A. Formulation and characterization of palm olein/caprylic triglycerides ester based emulgel for topical use. Afr. J. Pharm. Res. Dev. 2020, 12, 172-180.

13. Abbasalipourkabir, R.; Salehzadeh, A.; Abdullah, R. Characterization and stability of nanostructured lipid carriers as drug delivery system. Pak. J. Biol. Sci. 2012, 15, 141-146. [CrossRef]

14. Abdulkarim, M.F.; Abdullah, G.Z.; Chitneni, M.; Mahdi, E.S.; Yam, M.F.; Faisal, A.; Salman, I.M.; Ameer, O.Z.; Sahib, M.N.; Absulsattar, M.Z.; et al. Formulation and characterization of palm oil esters based nano-cream for topical delivery of piroxicam. Int. J. Drug Deliv. 2010, 2, 287-298. [CrossRef]

15. Deepa, M.K.; Karthikeyan, M.; Abhay, A.D.; Shruti, P.C.; Omkar, S.D.; Satish, R.C. Comprehensive review on solid lipid nanoparticles. Ann. Pharmacol. Pharm. 2020, 5, 1190.

16. Bhushan, P. (Ed.) Encyclopedia of Nanotechnology; Springer: Berlin/Heidelberg, Germany, 2012.

17. Madan, J.R.; Khude, P.A.; Dua, K. Development and evaluation of solid lipid nanoparticles of mometasone furoate for topical delivery. Int. J. Pharm. Investig. 2014, 4, 60-64. [CrossRef] [PubMed] 
18. Mishra, V.; Bansal, K.K.; Verma, A.; Yadev, N.; Thakur, S.; Sudhakar, K.; Rosenholm, J.M. Solid lipid nanoparticles: Emerging colloidal nano drug delivery systems. Pharmaceutics 2018, 10, 191. [CrossRef]

19. Silva, J.C.; Borrin, T.R.; Ruy, P.; Brito, T.C.; Pinheiro, A.C.; Vicente, A.A.; Pinho, S.C. Characterization, physicochemical stability, and evaluation of in vitro digestibility of solid lipid microparticles produced with palm kernel oil and tristearin. Food Sci. Technol. Camp. 2014, 34, 532-538. [CrossRef]

20. Goon, D.E.; Kadir, S.H.S.A.; Latip, N.A.; Rahim, S.A.; Mazlan, M. Palm oil in lipid-based formulations and drug delivery systems. Biomolecules 2019, 9, 64. [CrossRef]

21. Nahum, V.; Domb, A.J. Recent developments in solid lipid microparticles for food ingredients delivery. Foods 2021, 10, 400. [CrossRef]

22. Lim, W.H.; Tan, Y.J.; Lee, C.S.; Er, H.M.; Wong, S.F. Peparation and optimization of palm-based lipid nanoparticles loaded with griseofulvin. Iran. J. Pharm. Res. 2017, 16, 451-461.

23. Loganathan, R.; Subramaniam, K.M.; Radhakrishnan, A.K.; Choo, Y.; Teng, K. Health-promoting effects of red palm oil: Evidence from animal and human studies. Nutr. Rev. 2017, 75, 98-113. [CrossRef]

24. Ng, M.H.; Choo, Y.M.; Ma, A.N.; Chuah, C.H.; Hashim, N.A. Separation of Vitamin E (tocopherol, tocotrienol, and tocomonoenol) in Palm Oil. Lipids 2004, 39, 1031-1035. [CrossRef] [PubMed]

25. Ng, M.H.; Choo, Y.M. Chromatographic analyses of tocopherols and tocotrienols in palm oil. J. Chromatogr. Sci. 2012, 50, 283-286. [CrossRef]

26. Weissenberg, M.; Levy, A.; Schaeffler, I.; Menagem, E.; Barzilai, M. Rapid isocratic HPLC analysis of beta-carotene in red peppers (Capsicum annuum L.) and food preparations. Chromatographia 1997, 46, 399-403. [CrossRef]

27. Taufik, M.; Lioe, H.N.; Yuliana, N.D. Evaluation of major fatty acids determination in palm oil by gas chromatography-flame ionization detection. Agritech 2016, 36, 308-316. [CrossRef]

28. Shah, R.; Eldridge, D.; Palombo, E.; Harding, I. Optimisation and stability assessment of solid lipid nanoparticles using particle size and zeta potential. J. Phys. Sci. 2014, 25, 59-75.

29. Wei, L.; Yang, Y.; Shi, K.; Wu, J.; Zhao, W.; Mo, J. Preparation and characterization of loperamide-loaded dynasan 114 solid lipid nanoparticles for increased oral absorption in the treatment of diarrhea. Front. Pharmacol. 2016, 7, 332. [CrossRef]

30. Phetmung, H.; Sawatdee, S. Development of cosmetic cream containing a pharmaceutical cocrystal of salicylic and phenylalanine. Int. J. Appl. Pharm. 2019, 11,1-11. [CrossRef]

31. Gaspar, L.R.; Camargo, F.B., Jr.; Gianeti, M.D.; Maia Campos, P.M.B.G. Evaluation of dermatological effects of cosmetic formulations containing Saccharomyces cerevisiae extract and vitamins. Food Chem. Toxicol. 2008, 46, 3493-3500. [CrossRef] [PubMed]

32. Lademann, J.; Vergou, T.; Darvin, M.E.; Patzelt, A.; Meinke, M.C.; Voit, C.; Papakostas, D.; Zastrow, L.; Sterry, W.; Doucet, O. Influence of topical, systemic and combined application of antioxidants on the barrier properties of the human skin. Skin Pharmacol. Physiol. 2016, 29, 41-46. [CrossRef] [PubMed]

33. Zurko Research SL. Assessment in Human with Sensitive Skin of the Cutaneous Compatibility of a Cosmetical Product after a Single under Patch Application under Dermatological Control. (Test Element References 02/TC-PCS_150_15-001). 2015. Available online: https://nutritape.com/web/wp-content/themes/nutritape_theme/pdf/Report_02-TC-PTS_150_15-003_V1 .pdf (accessed on 1 March 2019).

34. Mwaurah, P.W.; Kumar, S.; Kumar, N.; Attkan, A.K.; Panghal, A.; Singh, V.K.; Garg, M.K. Novel oil extraction technologies: Process conditions, quality parameters, and optimization. Compr. Rev. Food Sci. Food Saf. 2020, 19, 3-20. [CrossRef] [PubMed]

35. Badawi, N.; El-Say, K.; Attia, D.; El-Nabarawi, M.; Elmazar, M.; Teaima, M. Development of pomegranate extract-loaded solid lipid nanoparticles; quality by design approach to screen the variables affecting the quality attributes and characterization. ACS Omega 2020, 5, 21712-21721. [CrossRef] [PubMed]

36. Kashanian, S.; Azandaryani, A.H.; Derakhshandeh, K. New surface-modified solid lipid nanoparticles using N-glutaryl phosphatidylethanolamine as the outer shell. Int. J. Nanomed. 2011, 6, 2393-2401.

37. Mura, P.; Maestrelli, F.; D'Ambrosio, M.; Luceri, C.; Cirri, M. Evaluation and comparison of solid lipid nanoparticles (SLNs) and nanostructured lipid carriers (NLCs) as vectors to develop hydrochlorothiazide effective and safe pediatric oral liquid formulations. Pharmaceutics 2021, 13, 437. [CrossRef]

38. Makoni, P.A.; Wa Kasongo, K.; Walker, R.B. Short term stability testing of efavirenz-loaded solid lipid nanoparticle (SLN) and nanostructured lipid carrier (NLC) dispersions. Pharmaceutics 2019, 11, 397. [CrossRef]

39. Khater, D.; Nsairat, H.; Odeh, F.; Saleh, M.; Jaber, A.; Alshaer, W.; Bawab, A.A.; Mubarak, M.S. Design, preparation, and characterization of effective dermal and transdermal lipid nanoparticles: A review. Cosmetics 2021, 8, 39. [CrossRef]

40. Understanding Skin-Skin pH. Available online: https://int.eucerin.com/about-skin/basic-skin-knowledge/skins-ph (accessed on 1 March 2021).

41. Sundram, K.; Sambanthamurthi, R.; Tan, Y. Palm fruit chemistry and nutrition. Asia Pac. J. Clin. Nutr. 2003, 12, $355-362$.

42. Iwata, H.; Shimada, K. Formulas, Ingredients and Production of Cosmetics: Technology of Skin-and Hair-Care Products in Japan; Springer: Berlin/Heidelberg, Germany, 2013.

43. Constantin, M.; Poenaru, E.; Poenaru, C.; Constantin, T. Skin hydration assessment through modern non-invasive bioengineering technologies. Maedica J. Clin. Med. 2014, 9, 33-38. 
44. Akdeniz, M.; Gabriel, S.; Lichterfeld-Kottner, A.; Blume-Peytavi, U.; Kottner, J. Transepidermal water loss in healthy adults: A systematic review and meta-analysis update. Br. J. Dermatol. 2018, 179, 1049-1055. [CrossRef]

45. Ganceviciene, R.; Liakou, A.I.; Theodoridis, A.; Makrantonaki, E.; Zouboulis, C.C. Skin anti-aging strategies. Derm.-Endocrinol. 2012, 4, 308-319. [CrossRef] [PubMed]

46. Dumoulin, M.; Gaudout, D.; Lemaire, B. Clinical effects of an oral supplement rich in antioxidants on skin radiance in women. Clin. Cosmet. Investig. Dermatol. 2016, 9, 315-324. [CrossRef]

47. Bino, S.D.; Duval, C.; Bernerd, F. Clinical and biological characterization of skin pigmentation diversity and its consequences on UV impact. Int. J. Mol. Sci. 2018, 19, 2668. [CrossRef] [PubMed]

48. Kao, Y.; Chuang, T.; Chao, S.; Yang, J.; Lin, Y.; Huang, H. Evaluation of the Antioxidant and Melanogenesis Inhibitory Properties of Pracparatum Mungo (Lu-Do Huang). J. Tradit. Complement. Med. 2013, 3, 163-170. [CrossRef] [PubMed] 